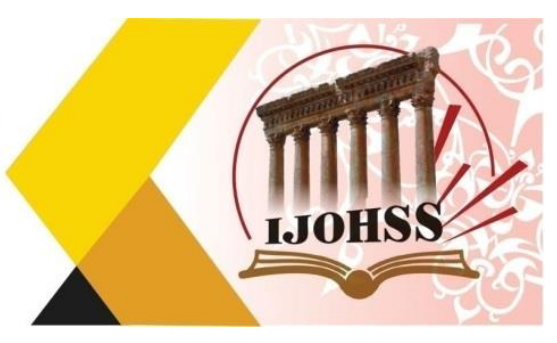

\title{
أزمة الهوية العربية الجامعة ما بين الواقع واعادة التشكيل
}

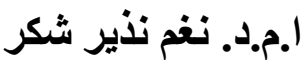 \\ قرم الدراسات الاقليمية والدولية فيكرية \\ مركز الاراسات الاستراتيجية والدولية الألية

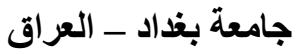

kaylanoo.alrassam@gmail.com البريد الالكتروني

الملخص

أن الدولة العربية المعاصرة تواجه، في ظل المتغيرات التي صاحبت العولمة، خطرين أساسيين هما خطر الحروب الأهلية التي تهدد بتفتيت السيادة وتمزيق الوحدة الوطنية لكل بلد عربي وخطر انتزاع السيادة ونقلها إلى كيانات دولية وإقليمية اكبر كالنظام الثرق أوسطي الجديد او ترتيبات الثراكة الأوروبية المتوسطية .وتتطلب مو اجهة الخطر الأول تعديل العلاقة الر اهنة بين الدولة والمجتمع من علاقة تقوم على التسلط والعنف إلى علاقة تقوم على القانون ،وترتكز على علاقات المواطنة، بما تعنيه من حقوق متساوية أمام القانون وان تعمل على صهر تلك التكوينات في بنية اجتماعية جديدة تعلو على كل التعدديات الصغرى، وصولاً إلى إدماج هذه التكوينات المختلفة في ثقافة وطنية جامعة من خلال مشروع وطني يحظ بقبول سياسي عام. 


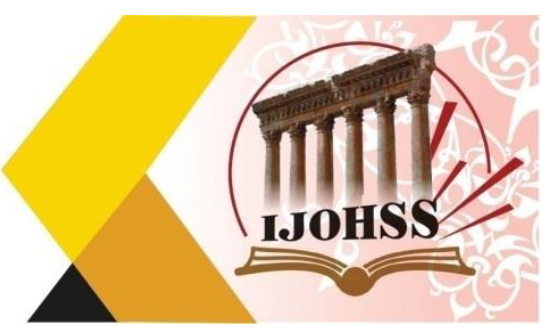

\title{
The Crisis of the Arab Identity that Combines Reality and Reconfiguration
}

\author{
Assist. Prof. Dr. Nagham Natheer Shukur \\ Department of Regional and International Studies \\ Center for Strategic and International Studies \\ University of Baghdad - Iraq \\ Email kaylanoo.alrassam@gmail.com
}

\begin{abstract}
The contemporary Arab state faces, in light of the changes that have accompanied globalization, two main dangers the danger of civil wars that threaten to fragment the sovereignty and tear apart the national unity of every Arab country and the danger of seizing sovereignty and transferring it to larger international and regional entities, such as the new Middle Eastern order or the Euro-Mediterranean partnership arrangements. Facing the first danger, amending the current relationship between the state and society from a relationship based on domination and violence to a relationship based on law, based on citizenship relations, which means equal rights before the law, and working to fuse these formations into a new social structure that surpasses all minor pluralities. Integration of these various formations into an inclusive national culture through a national project that has general political acceptance.
\end{abstract}

Keywords Arab identity, globalization, citizenship. 


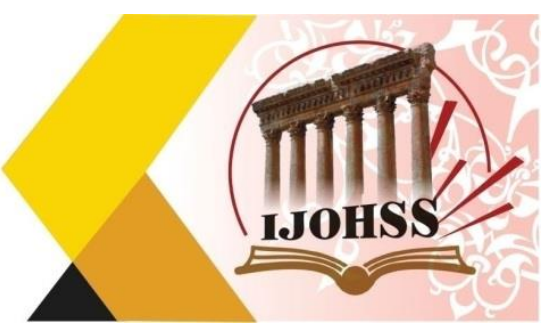

المقدمة

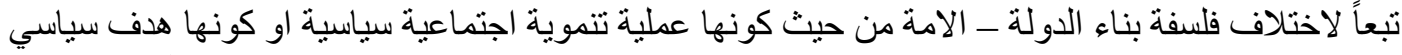

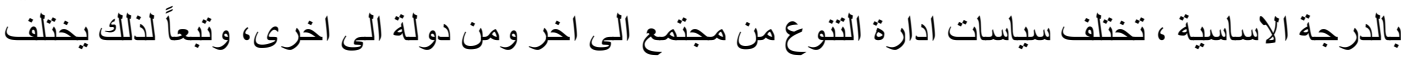

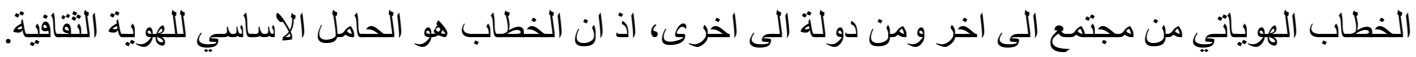

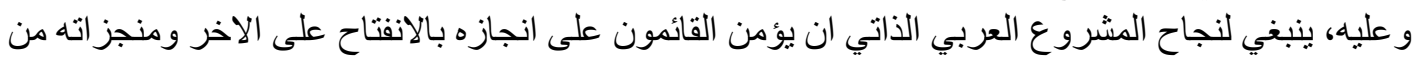

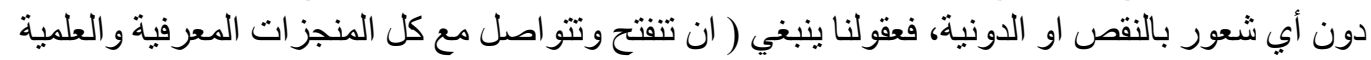

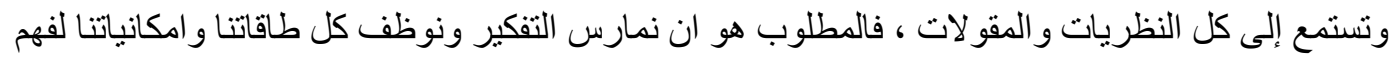

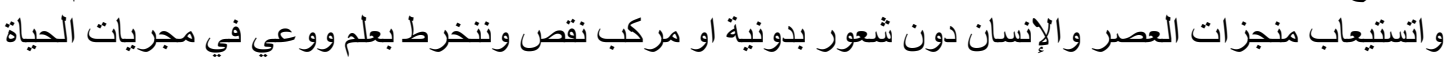

تعد الهوية الثقافية لاي شعب القدر الثابت و الجو هري و المشترك من السمات و القسمات العامة التي تميز حضارته

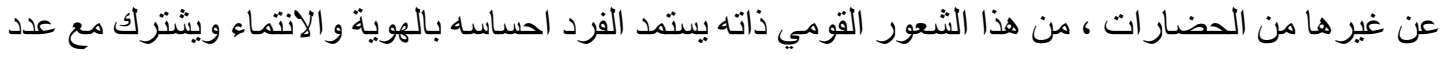
كبير من افر اد الجماعة في عدد من المكونات والاهداف وينتمي الى ثقافة مركبة من جملة من المعايير و الرموز

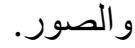

مشكلة البحث

يطرح البحث في مفاصله اسباب الصبيرورة التفككية للاولة العربية، موضحاً ان القوى الاستعمارية حين حددت

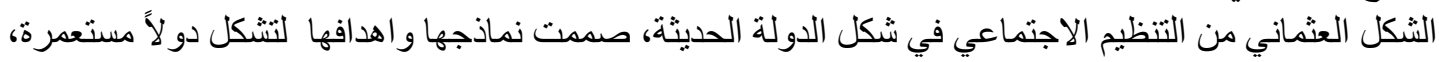

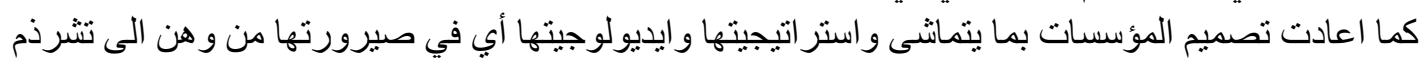

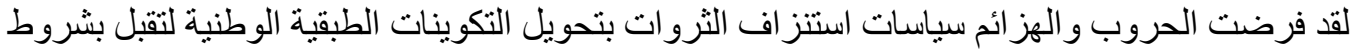

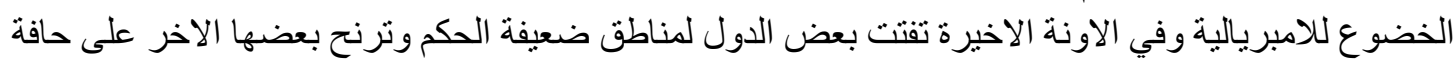

فرضية البحث

هناك ازمة للهوية العربية في العالم العربي فالهوية لاتبنى ولا تتطور الا في ظل التفاعلات الاجتماعية وفي اطار

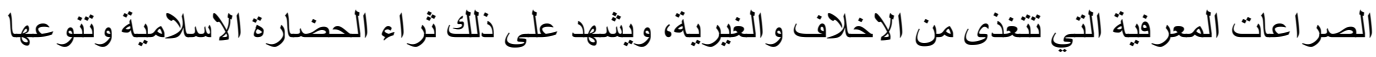

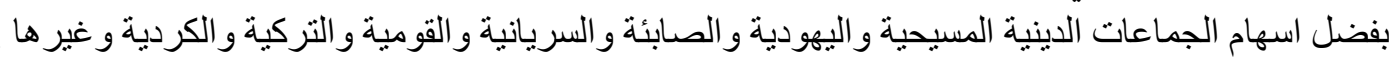

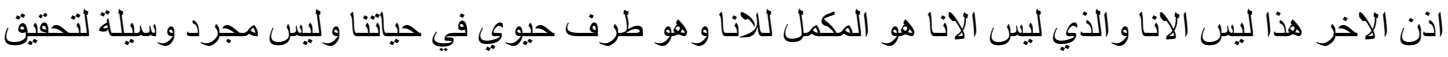

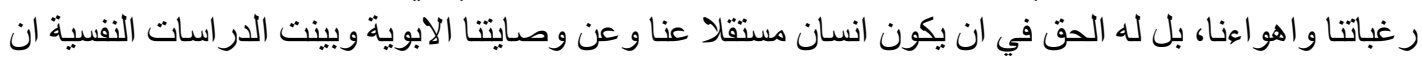
اكتثاف الذات و الوعي بها يمر حتما بتجربة ان بكرن التعايش مع الاخر المختلف. منهجية البحث

ابعاد الموضوع و اشكالاته المتعددة دفعت باتجاه استخدام اكثر من منهج علمي و عليه فقد اتبعنا في هذه الدر اسة التها

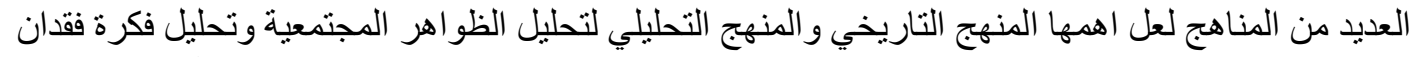

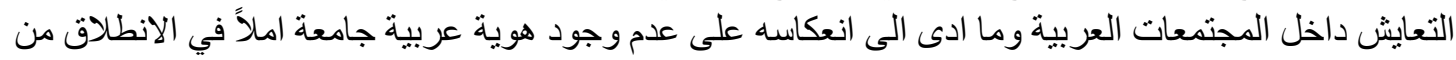

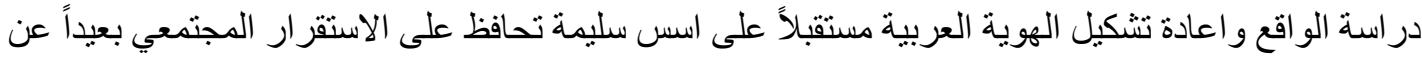

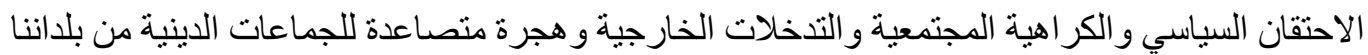
المبحث الاول بعنوان واقع الهوية العربية الذي ينقسم الى محورين الاول اتجاهات التعصب في الواقع الاجتماعي 


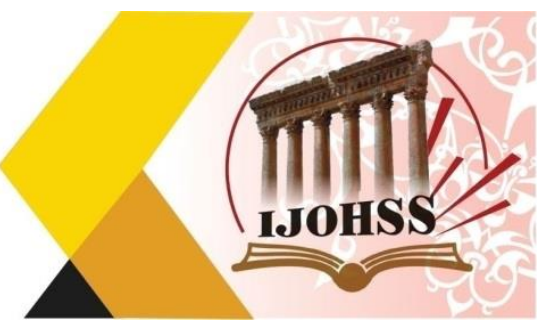

العربي و الثناني ثقافة الكر اهية والعنف بين الجماعات في الواقع الاجتماعي العربي.

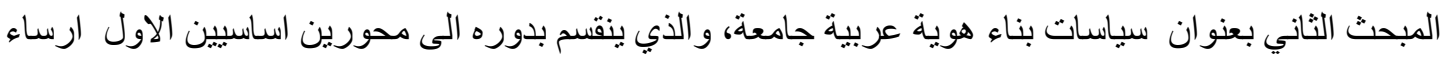
ثقافة سياسية مشاركة و الثاني المعالجات و الحلول من منظور الامن المجتمعي سبيلاً لبناء هوية عربية جامعة. ثم ينتهي البحث الى خاتمة واستنتاجات مئنات المعال

\section{المبحث الاول واقع الهوية العربية}

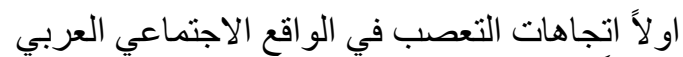

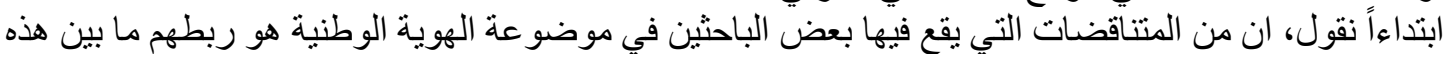

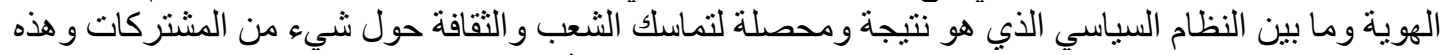

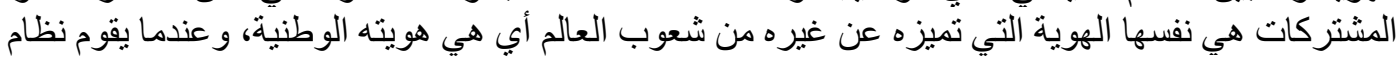

سياسي فوق هذه الهوية.

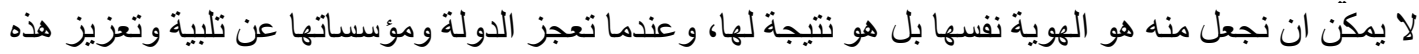

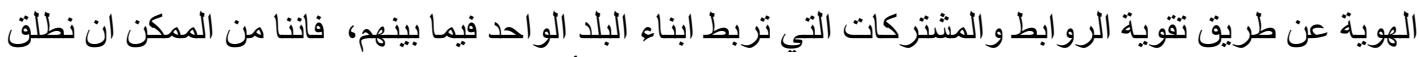

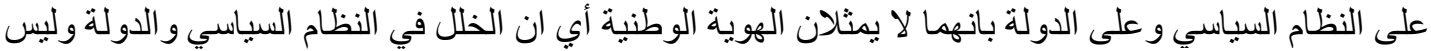

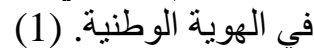
اذن فالمجتمع المدني هو حلقة الوصل بين السلطة و المجتمع ، و هو المسؤول عن توضيح افكار السلطة وتطلعاتها

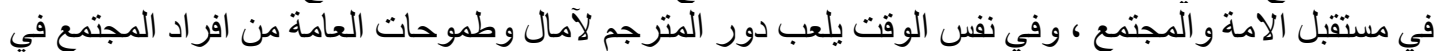

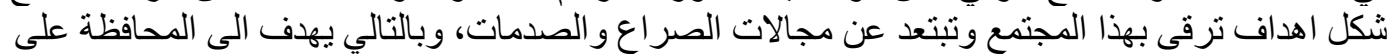

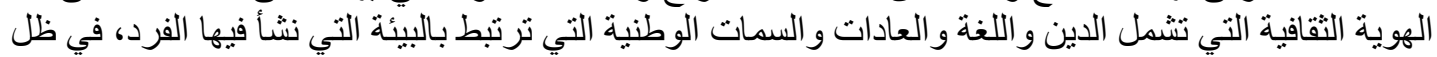

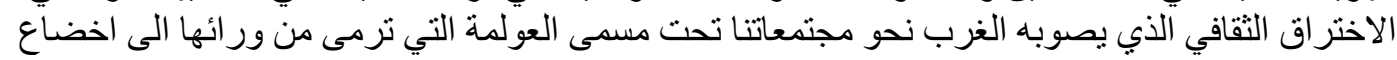

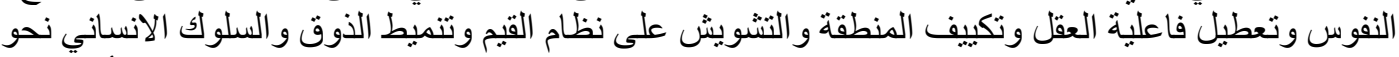

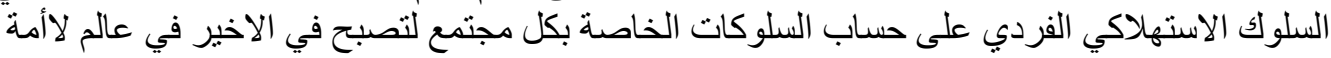

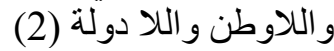

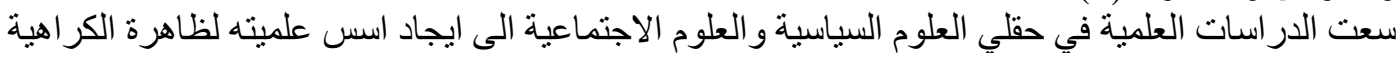

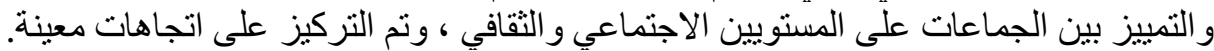

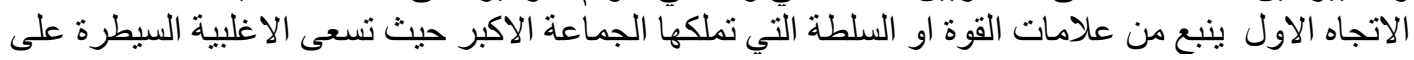

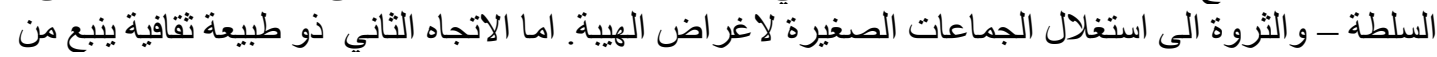

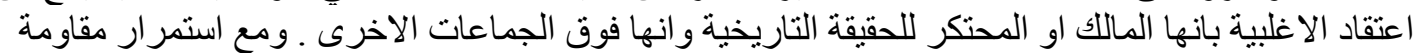

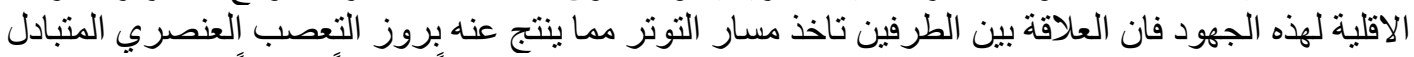

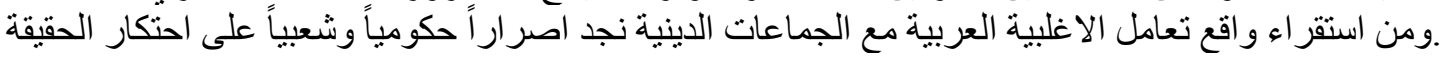

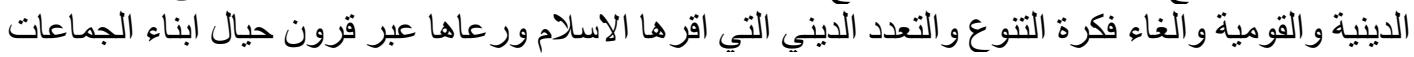

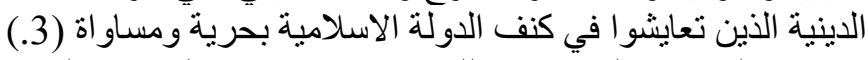

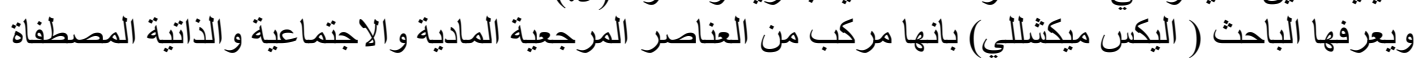

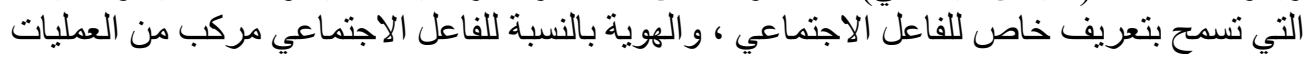

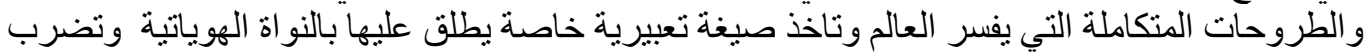

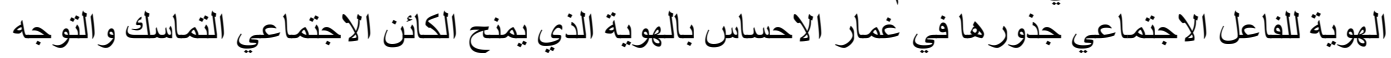

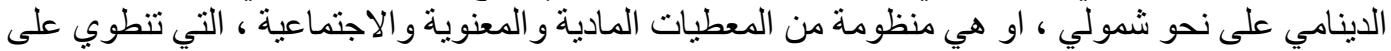

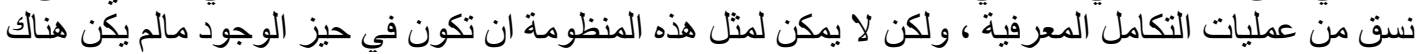

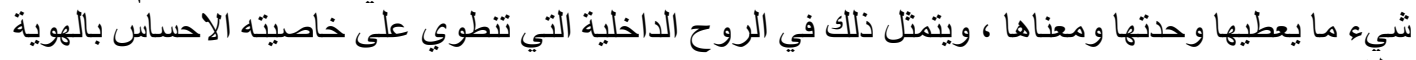

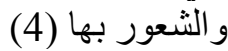
و على هذا الاساس فان فاعلية عملية التمكن السياسي مسألة في غاية الاهمية حيث تتضمن تبنى سياسات 
International Journal on Humanities and Social Sciences

website:www.ijohss.com

Email:editor@ijohss.com

العداد(22) يوليو 2021

ISSN: 2415 - 4822

Volume (22) July 2021

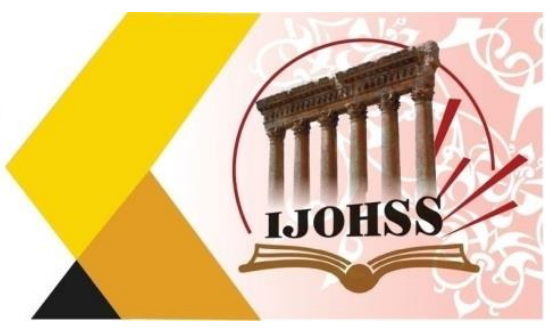

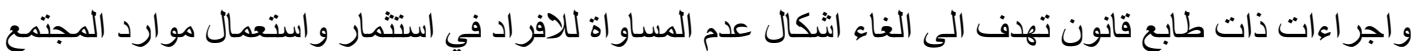

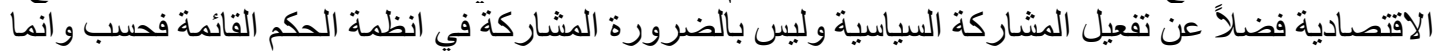

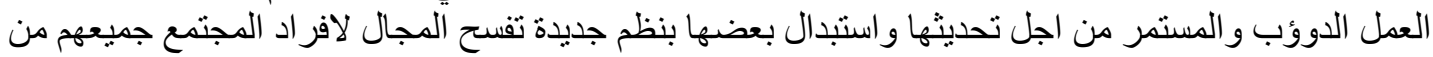

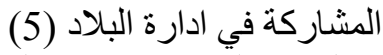

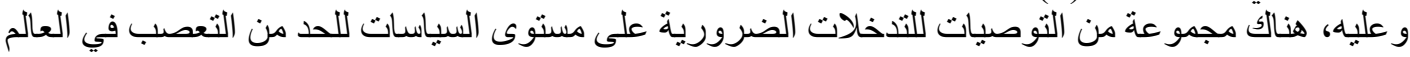
العربي-

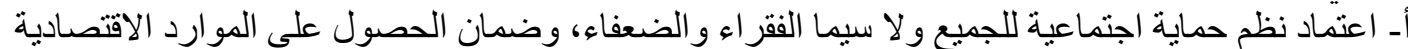

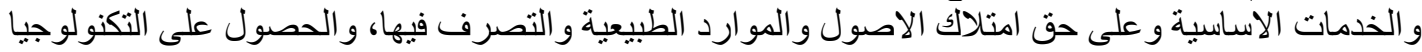

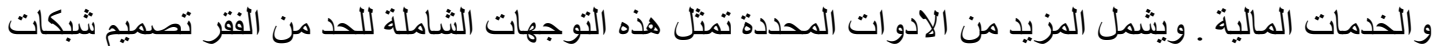

امان اجتماعي تعالج تحديداً فقر الدخل ، وتشمل هذه التحو التحو لات النقدية و المساعدات الغذائية ودعم الاسكان وتوسيع شبكة الضمان و التامين الاجتماعبين.

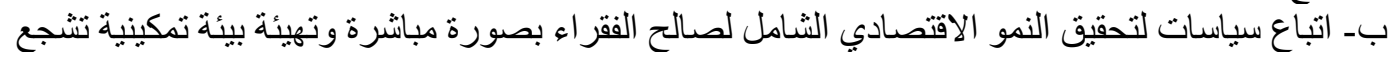

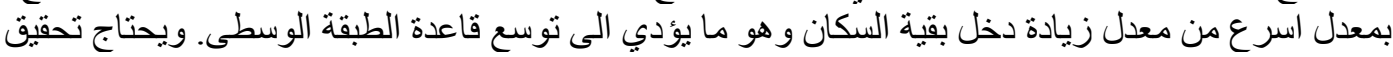

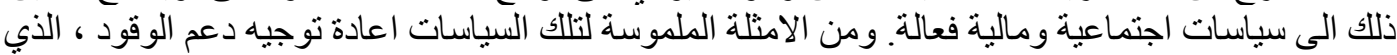

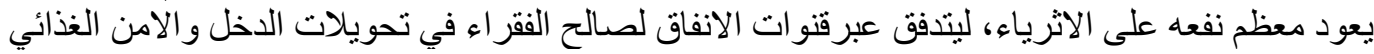

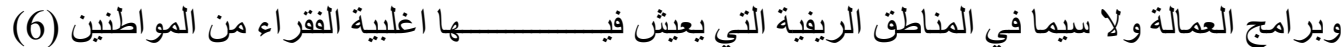

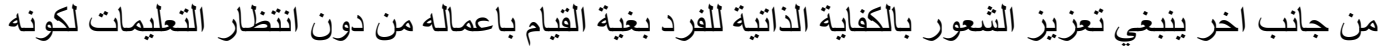

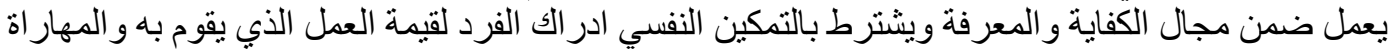

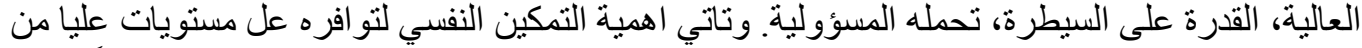

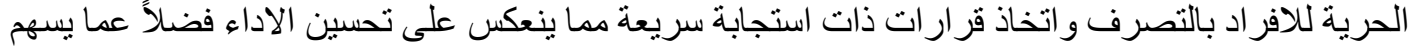

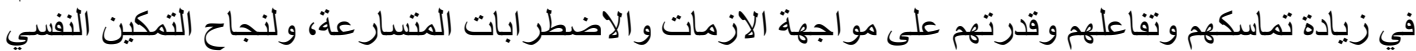

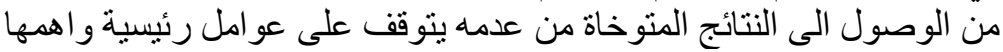

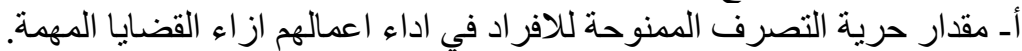

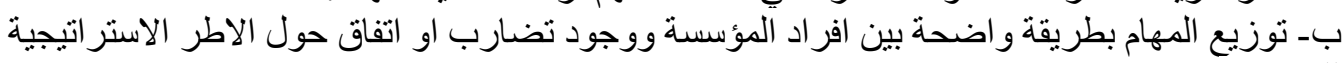
اللمؤسسة. تــ مقدار القوة في اتخاذ القرار وتحمل المسؤولية از اء ادوار كل فرئ فرد في المؤسسة.

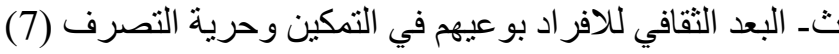

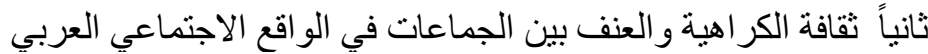

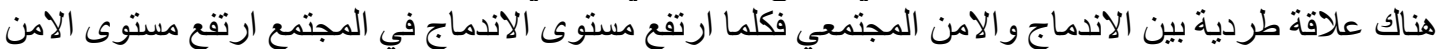

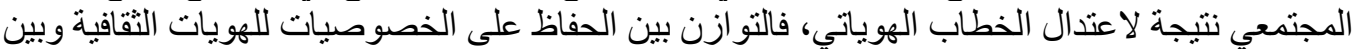

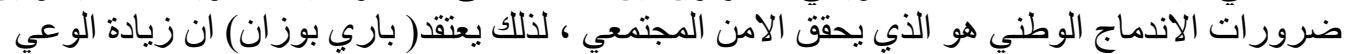

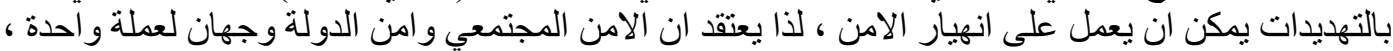

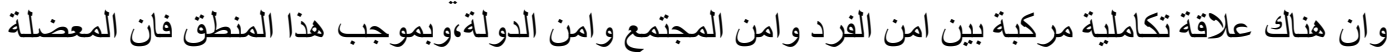

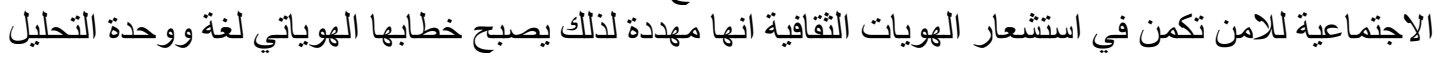

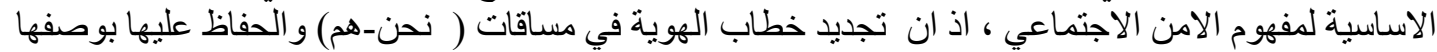

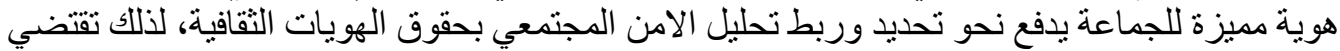

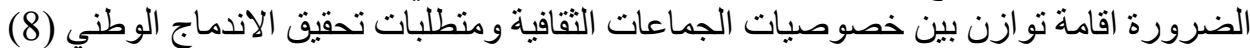

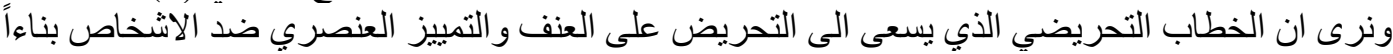

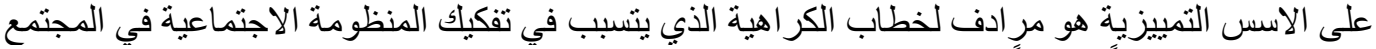

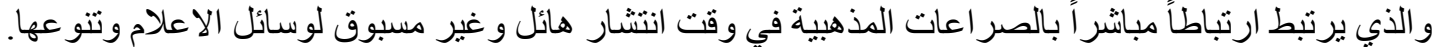

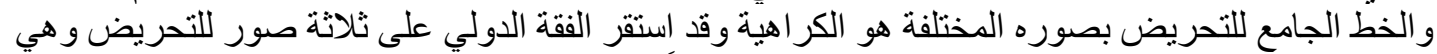

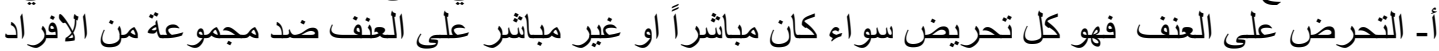


International Journal on Humanities and Social Sciences

website:www.ijohss.com

Email:editor@ijohss.com

ISSN: $2415-4822$

العدد(22) يوليو 2021

Volume (22) July 2021

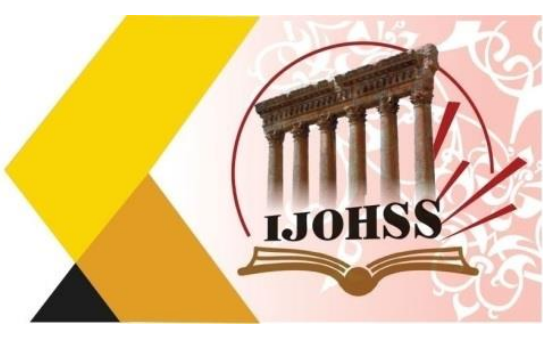

على اساس التمييز العنصري ويؤدي بالنتيجة الى العنف.

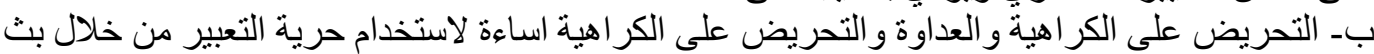

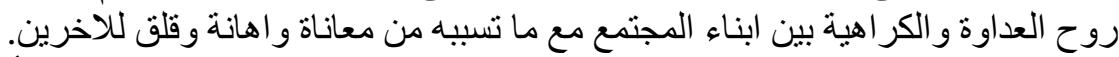

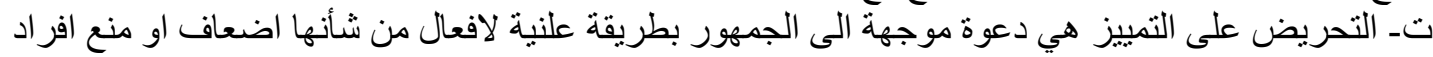

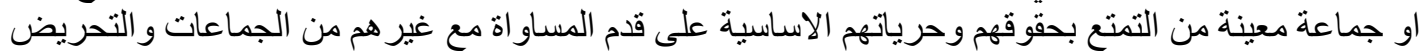

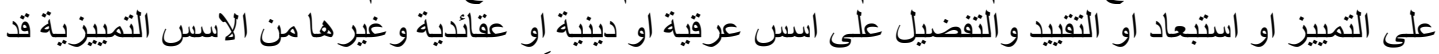

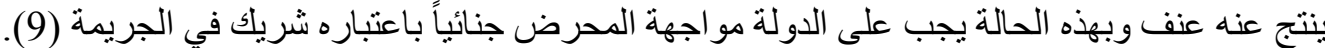

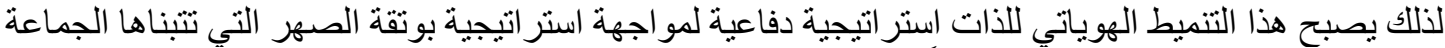

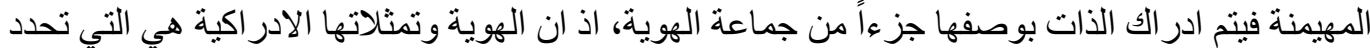

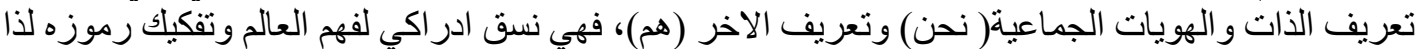

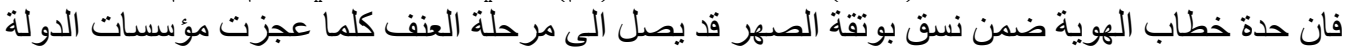

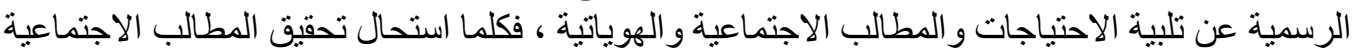

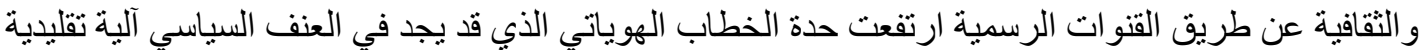

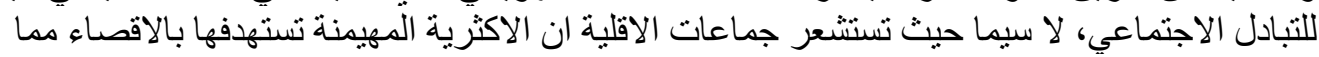

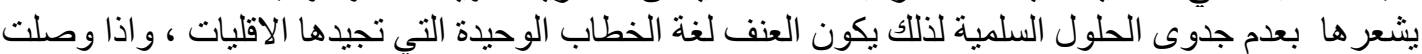

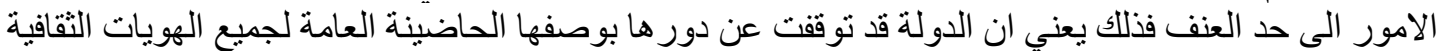

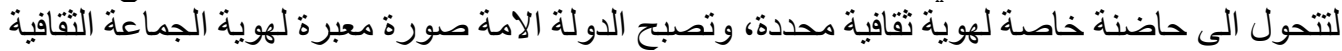

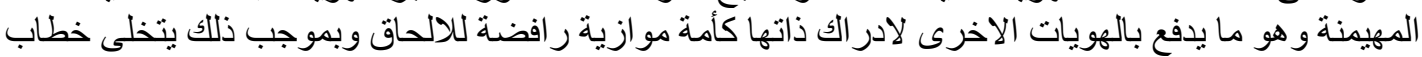

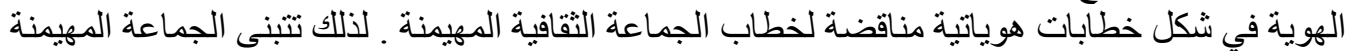
استر اتيجية بوتقة الصهر وتنتج فيها جملة سياسات منها مثلاً

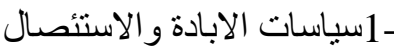

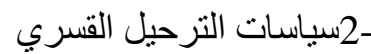

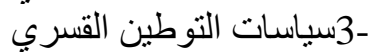

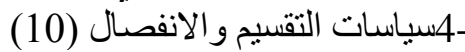

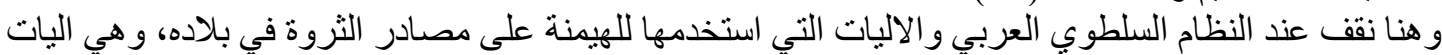

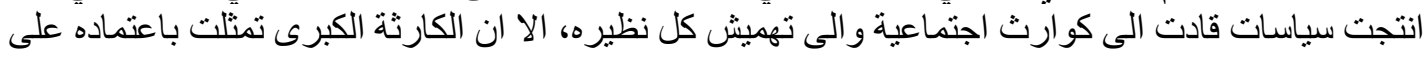

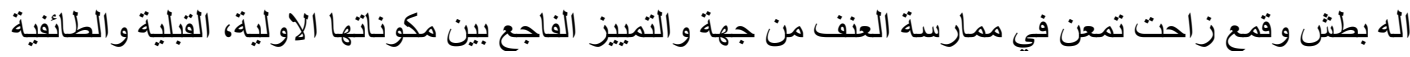

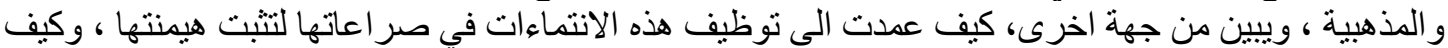

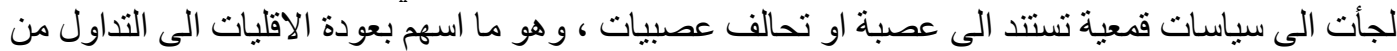

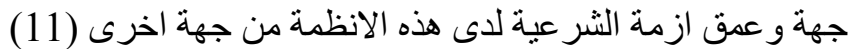

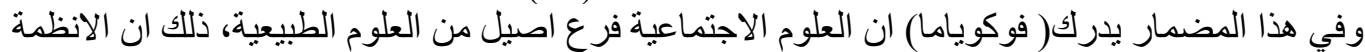

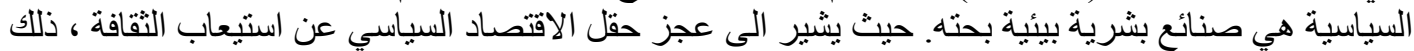

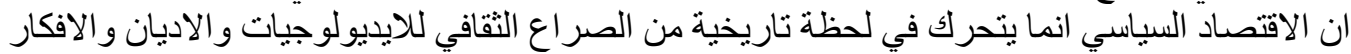

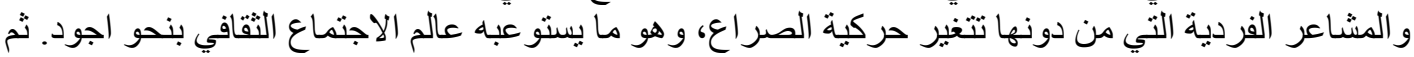

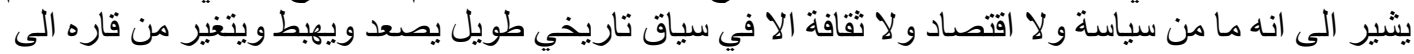

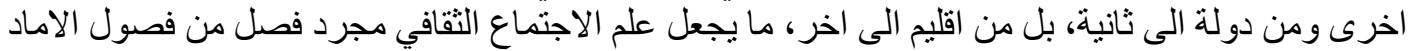

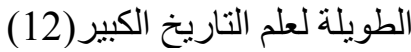

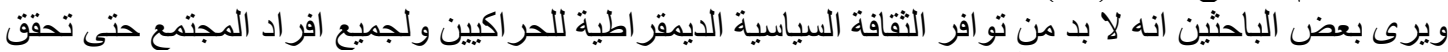

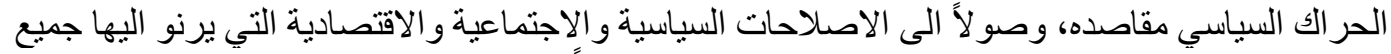

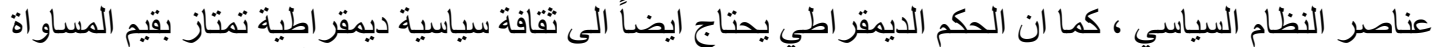

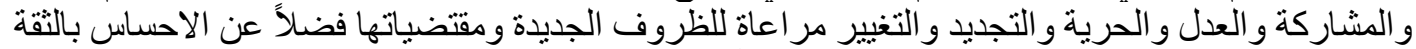

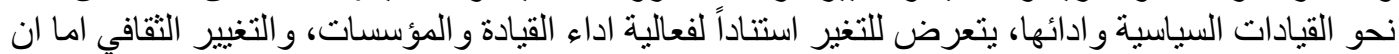


International Journal on Humanities and Social Sciences

website:www.ijohss.com

Email:editor@ijohss.com

ISSN: $2415-4822$

العداد(22) يوليو 2021

Volume (22) July 2021

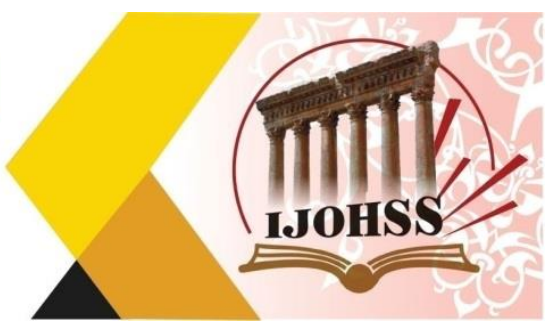

يكون بطريقة مخطط لها من اجل الوصول الى الاصلاح المنشود و اما بطريقة غير مخطط لها تشكلها الظروف

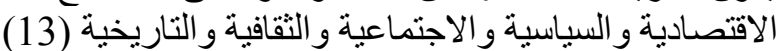

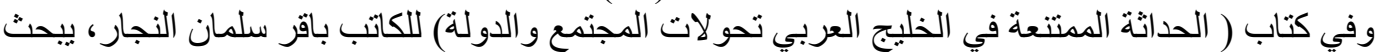

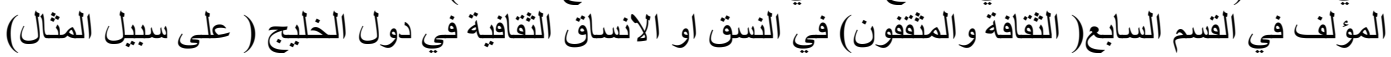

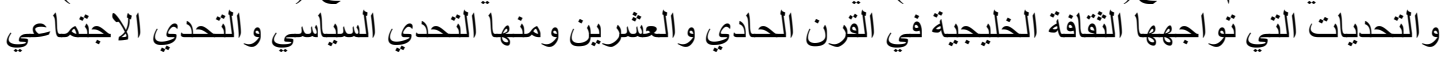

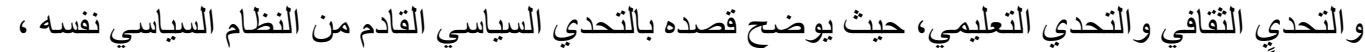

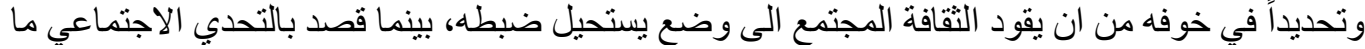

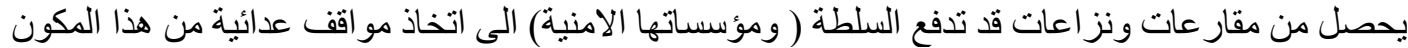

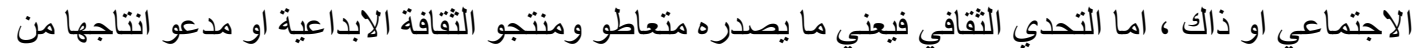

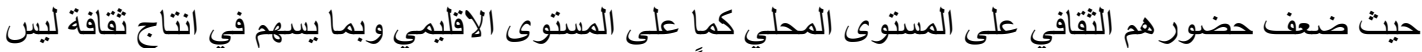

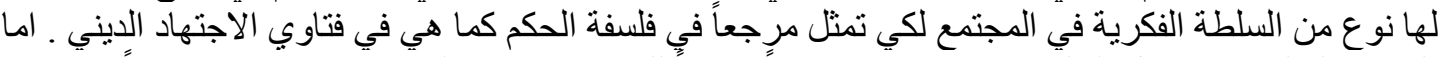

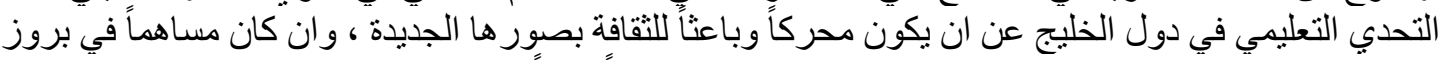

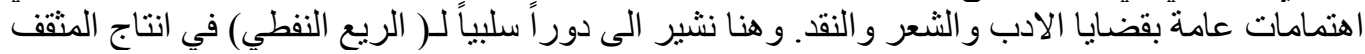

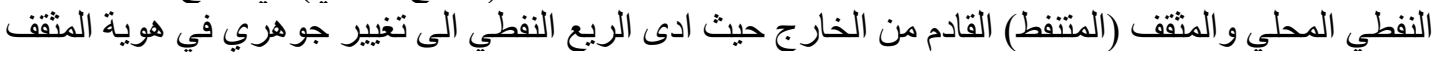

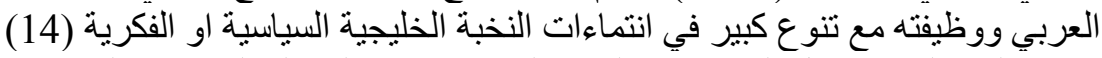

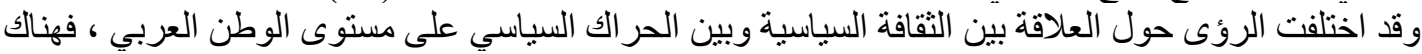

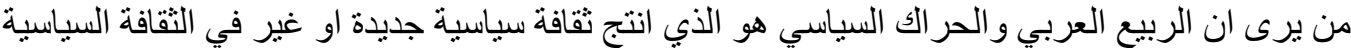

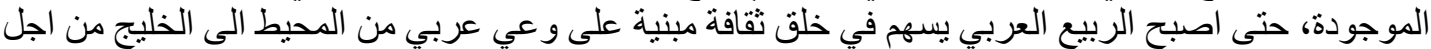

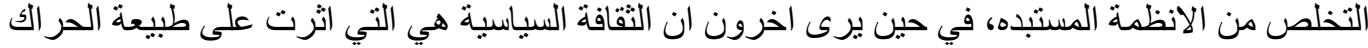

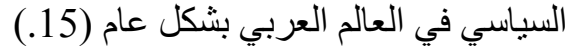

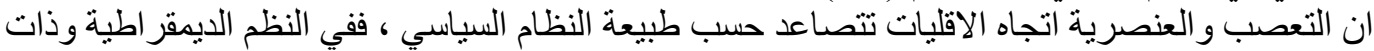

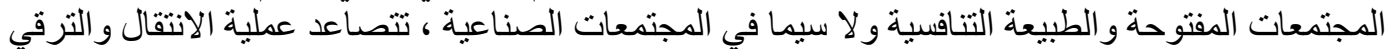

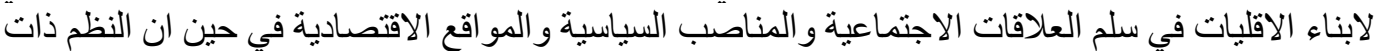

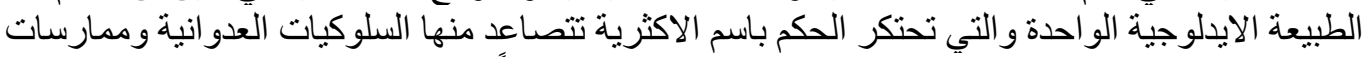

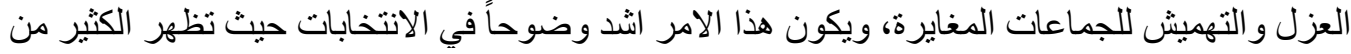

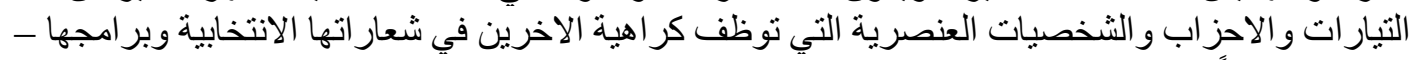

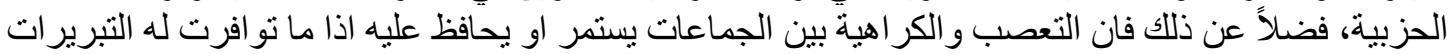

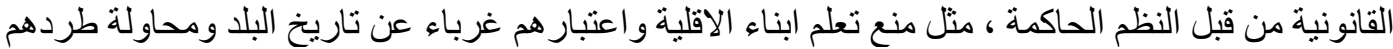

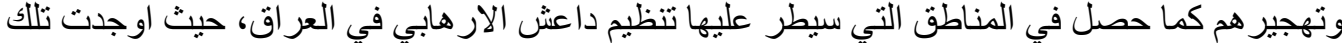

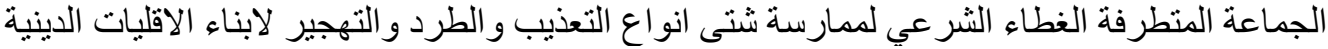

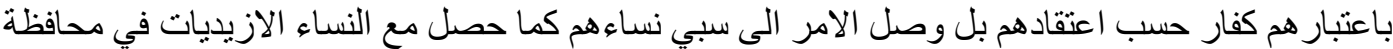

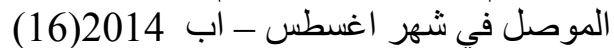

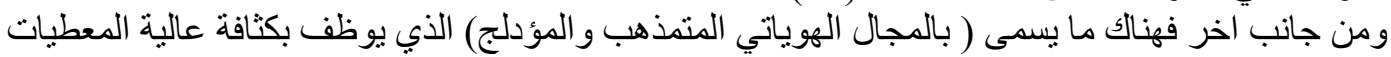

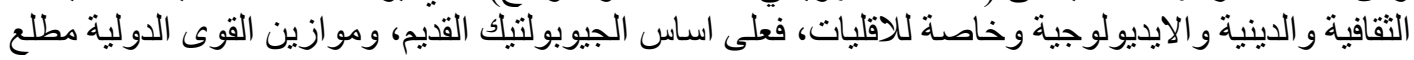

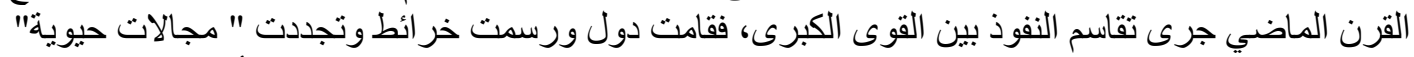

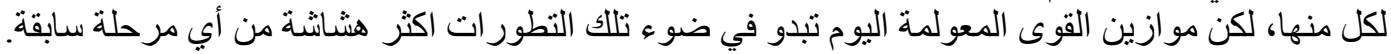

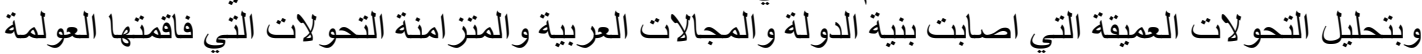

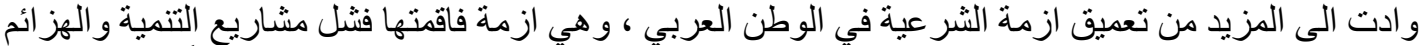

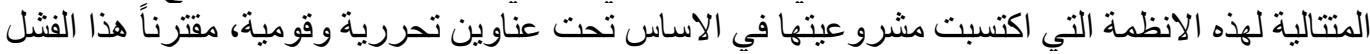

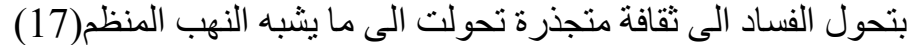

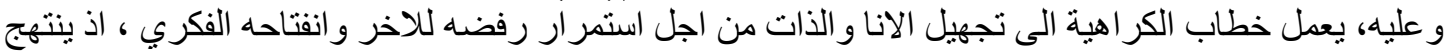

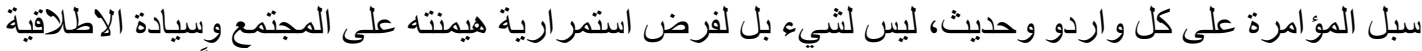

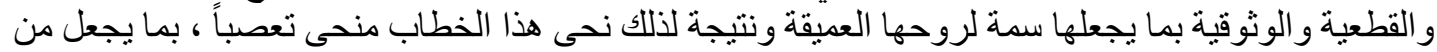


International Journal on Humanities and Social Sciences

website:www.ijohss.com

Email:editor@ijohss.com

يوليو 2021

(22) العداد)

ISSN: 2415 - 4822

Volume (22) July 2021

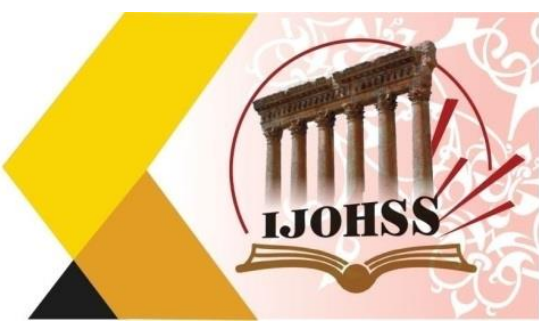

التعصب سمته الاساسية، و هذا التعصب تستثيره ثقافة طارئة او قديمة في المجتمع. و اذا لم بكن له قانون التون معين

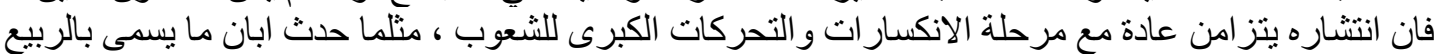

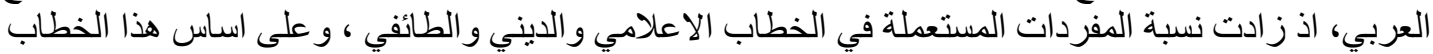

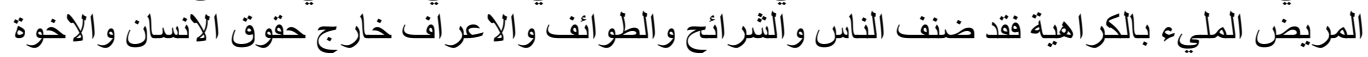

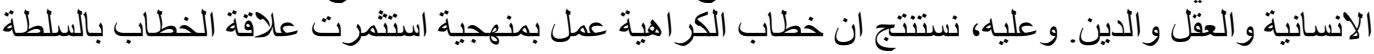

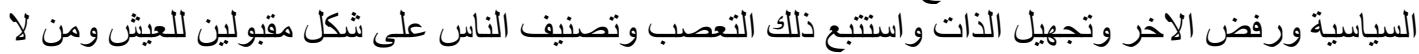

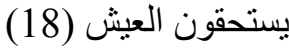

\section{المبحث الثاني}

اولاً ارساء ثقافة سياسية مشاركة

حقيقتاً تبدأ صورة تحديد الهوية من خلال التفاعل و الاندماج مع الاخرين، و هذا ما يؤكد على وجلى وجود هويات

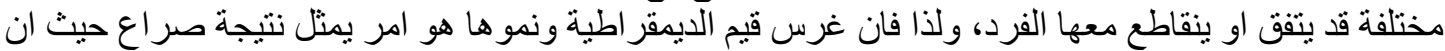

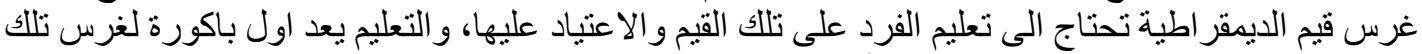

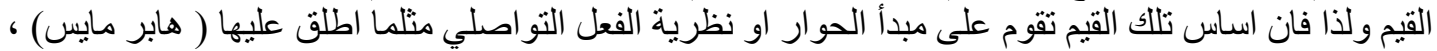

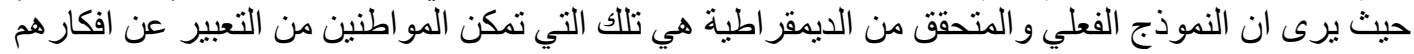

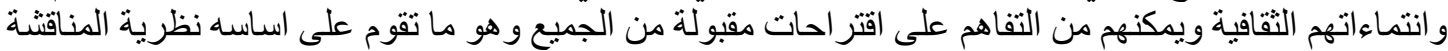

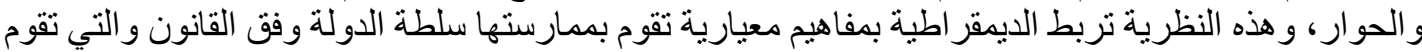

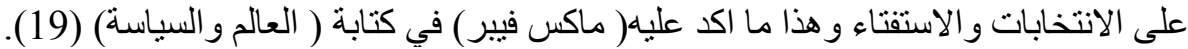

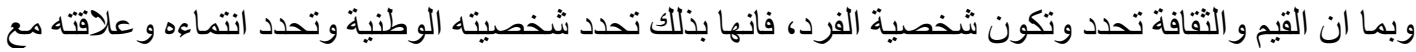

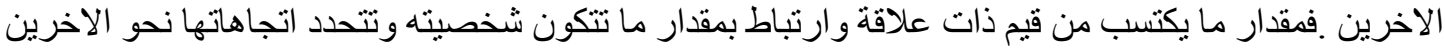

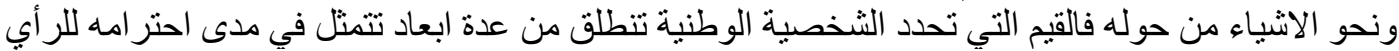

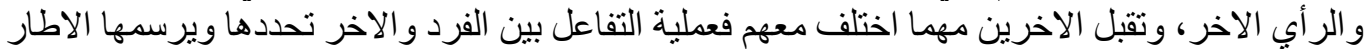

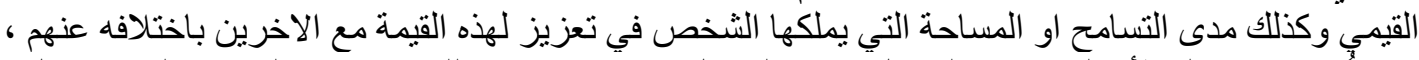

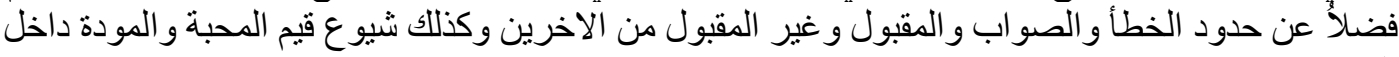
المجتمع وفي شخصيات الافر اد (20)

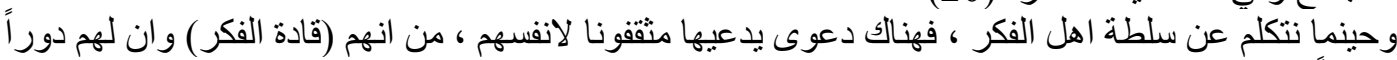

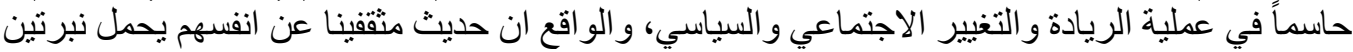

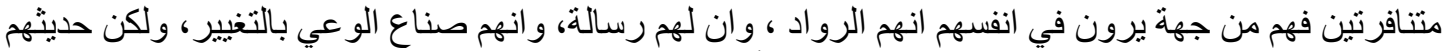

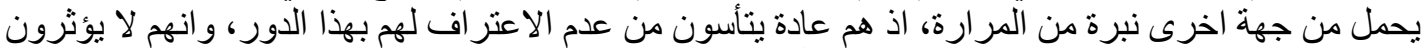

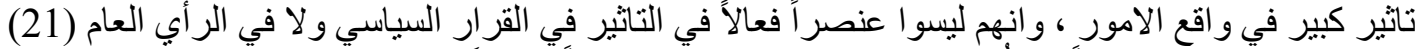

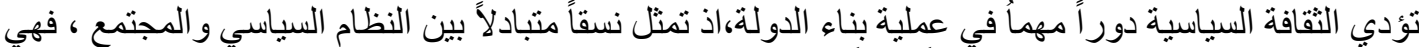

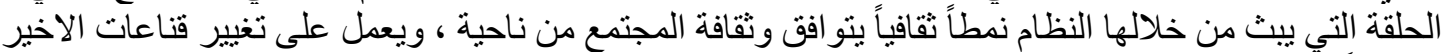

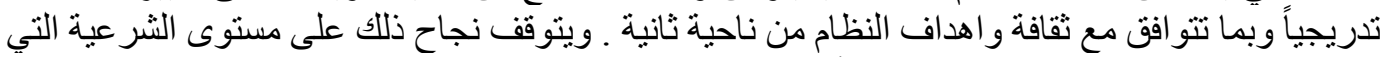

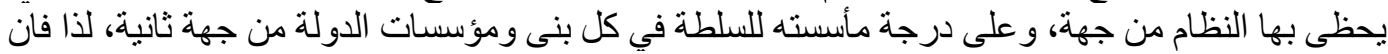

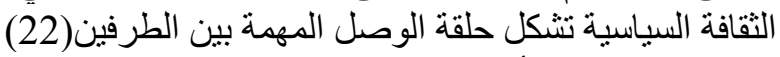

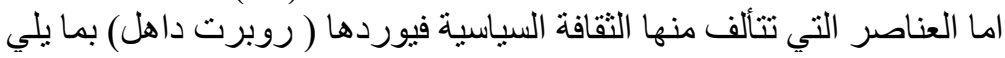

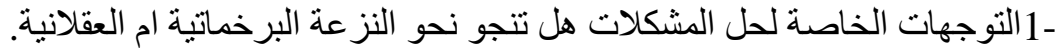

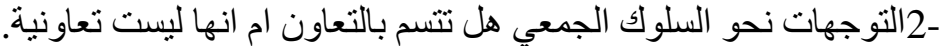

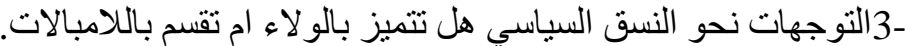
4-4التوجهات نحو الاشخاص الاخرين هل تغلب عليها الثقة ام تخلو من الثقة.و عليه يمكن تصور الثقافة السياسية 
International Journal on Humanities and Social Sciences

website:www.ijohss.com

Email:editor@ijohss.com

العدد(22) يوليو 2021

ISSN: $2415-4822$

Volume (22) July 2021

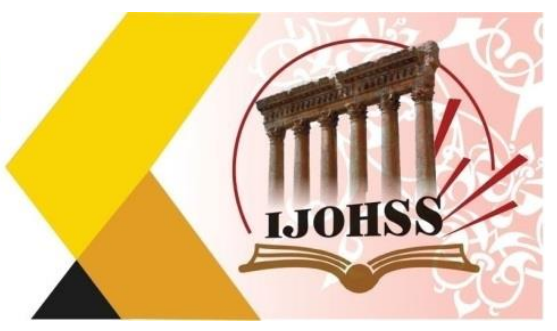

على انها البيئة او المناخ العاطفي او السايكولوجي و القيمي الذي تعمل داخله النظم و الانساق السياسية، وهي

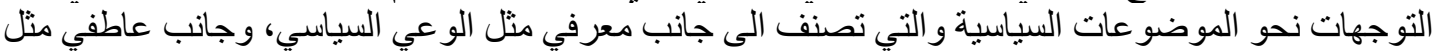

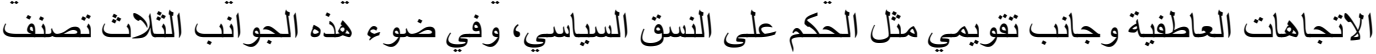

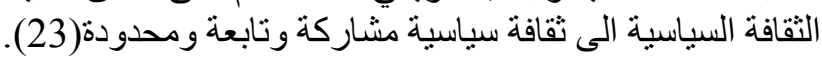

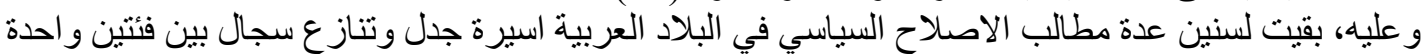

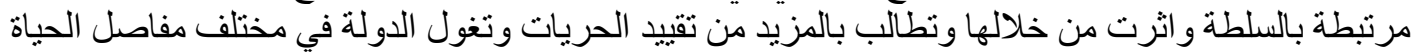

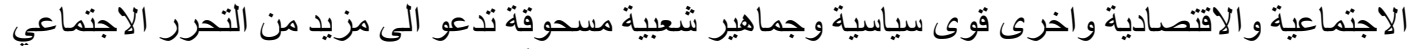

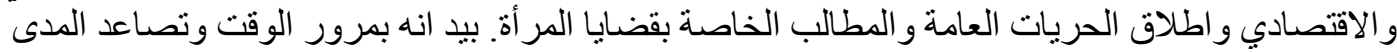

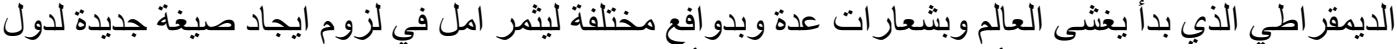

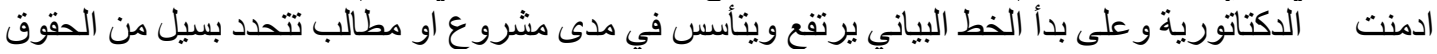
و الحريات حول سيادة القانون و اطلاق الحريات وتنظيم انتخابات و اعلان حوان حوار وطني وضمان حقوق

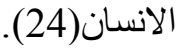

و عليه، تبرز صورة الثئقافة السياسية المشاركة و الموحدة كأفضل صيغة لبناء وحدة وطنية و اندماج اكثر رسوخاً

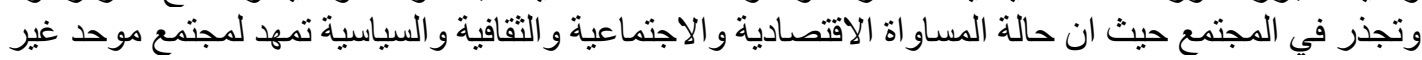

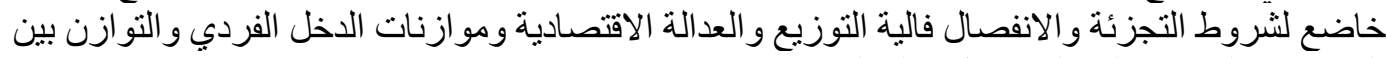

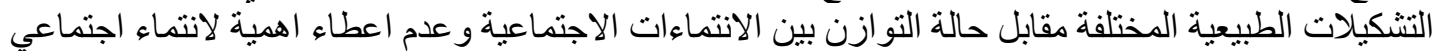

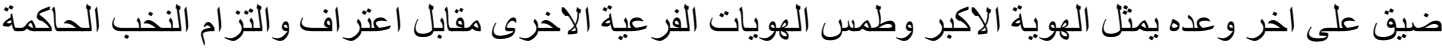

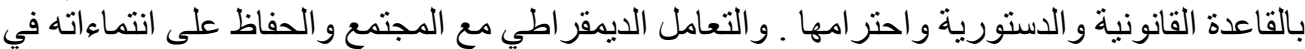

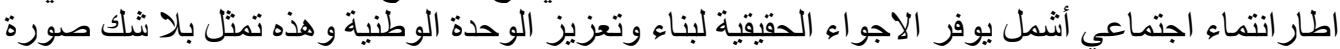

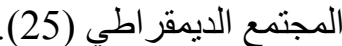

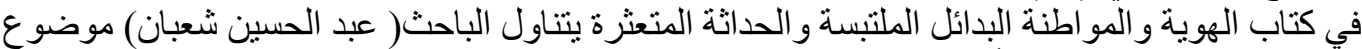

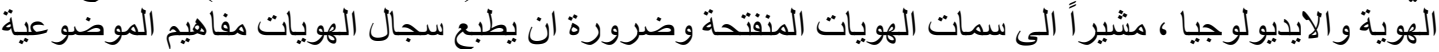

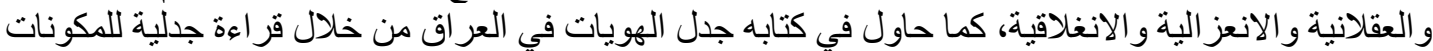

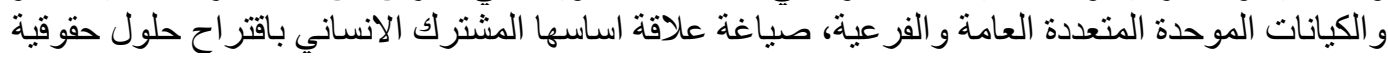

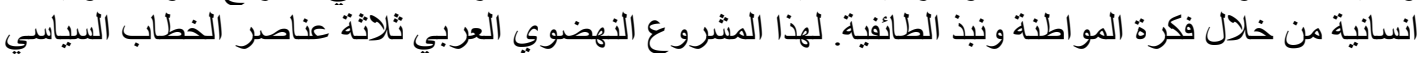

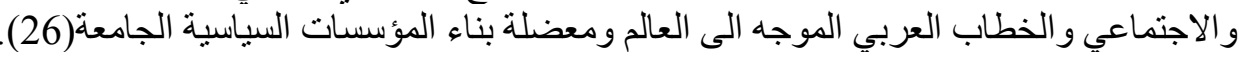

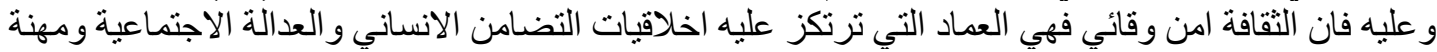

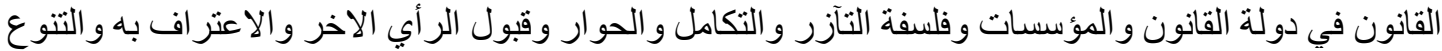

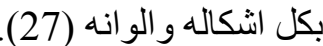

و هكذا اخذ دور الثقافة يتعاظم سواء على الهى الفرد او الثعب او الامة او الدولة ويزداد ناثثير ها على السياسة

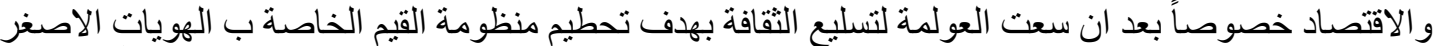

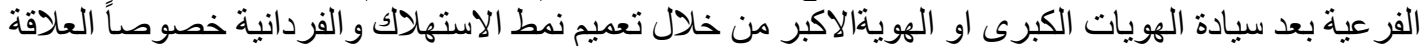

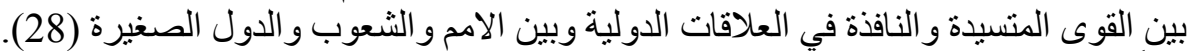

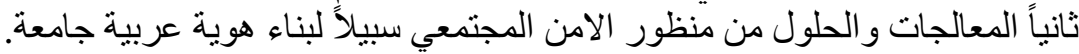

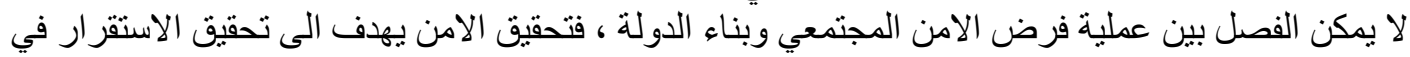

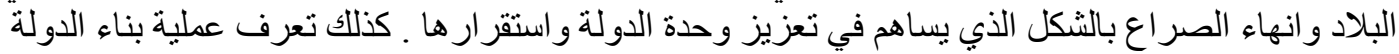

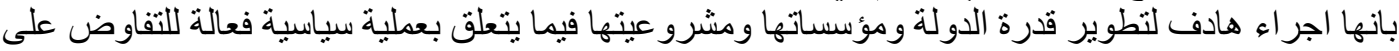

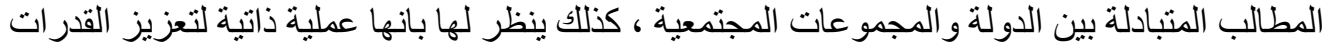

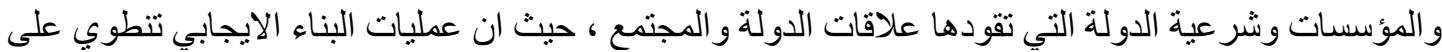

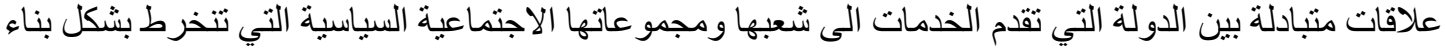

معها (29). (29).

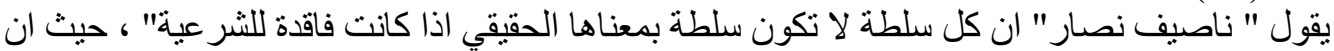
الثر عية هي مرجعية سياسية تكون خار ج النظام القانوني، بالمعنى الدقيق اذ تعود للافر اد ومن ور ائهم في التي 
International Journal on Humanities and Social Sciences

website:www.ijohss.com

Email:editor@ijohss.com

العدد(22) يوليو 2021

ISSN: 2415 - 4822

Volume (22) July 2021

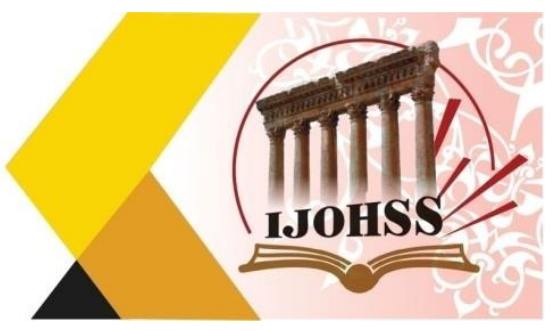

ممارسة السلطة من قبل الحكام ـوما يحكم المشرو عية هي مرجعية قانونية، بمعنى ان تقدير المشرو عية يتم

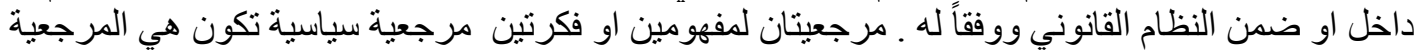

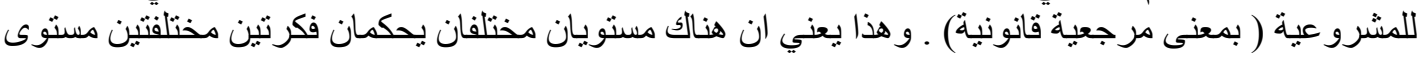

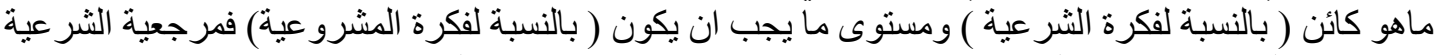

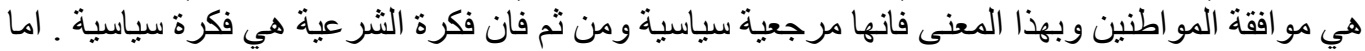

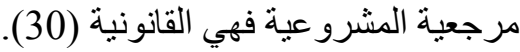

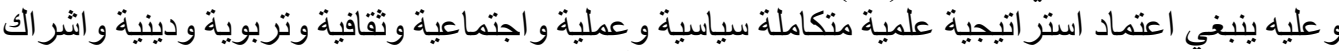

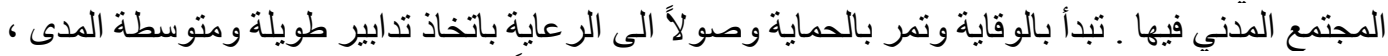

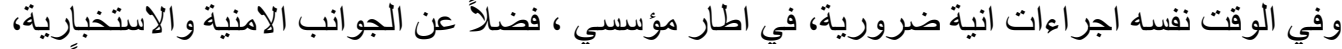

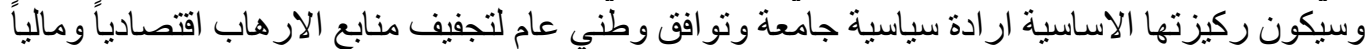

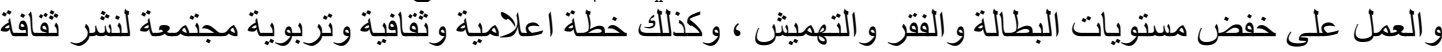

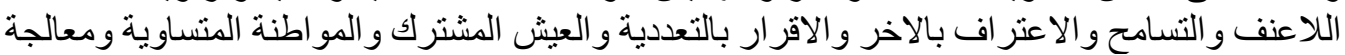

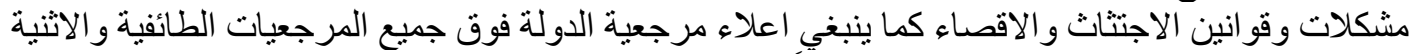

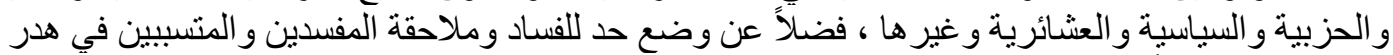

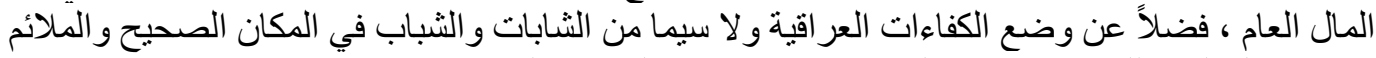

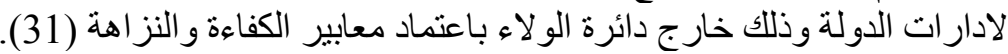

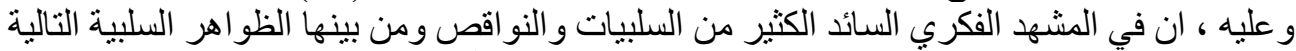

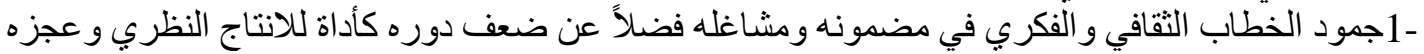

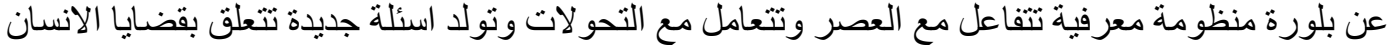

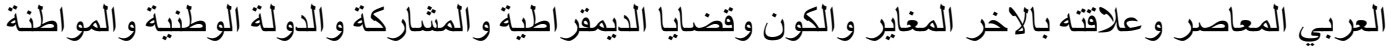

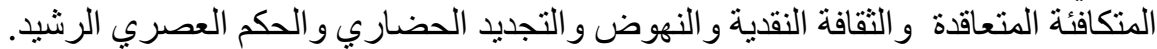

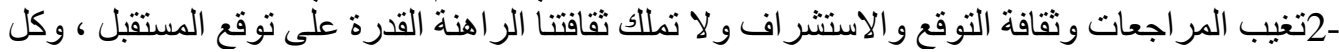

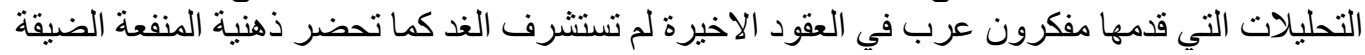

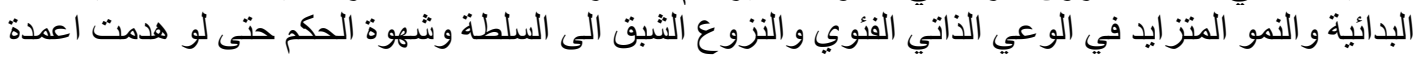

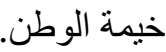
-3 الضبابية في التعامل مع قيم النزاهة ومواجية النهة الفساد وتداول السلطة في مؤسسات العمل النقابي و الاهلي

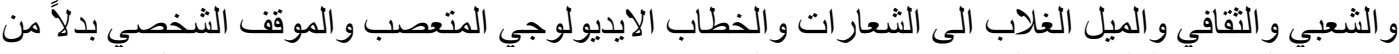

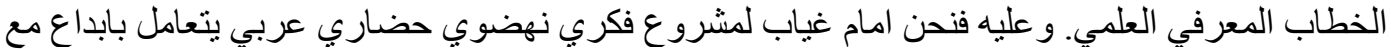

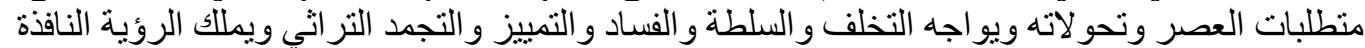
و والار ادة و الاليات اللازمة (32).

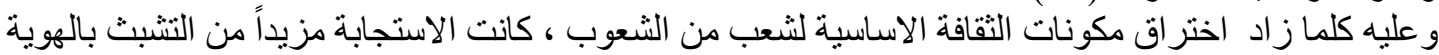

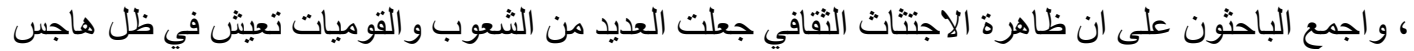

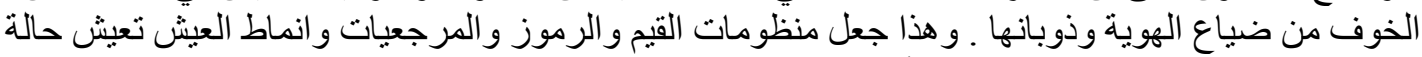

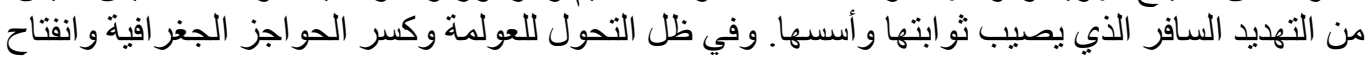

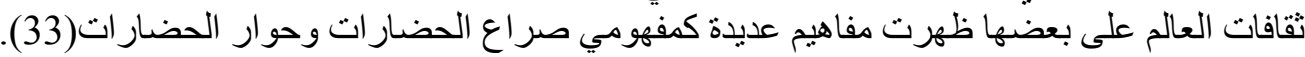

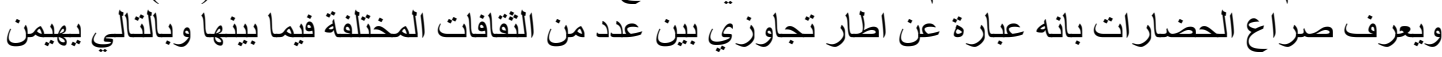

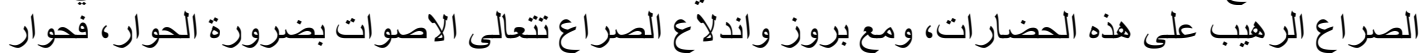

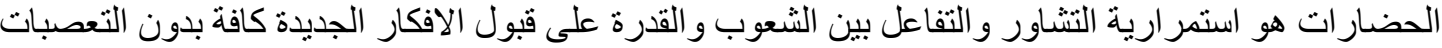

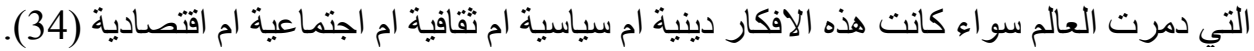

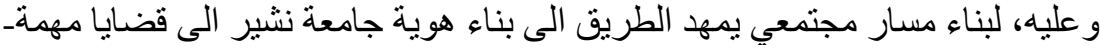

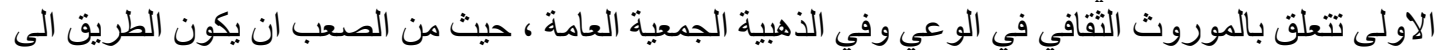

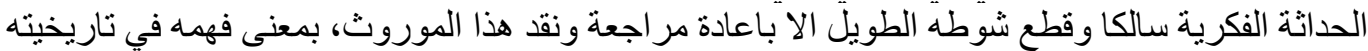

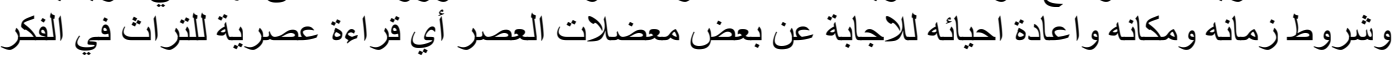


International Journal on Humanities and Social Sciences

website:www.ijohss.com

Email:editor@ijohss.com

ISSN: $2415-\mathbf{4 8 2 2}$

العداد(22) يوليو 2021

Volume (22) July 2021

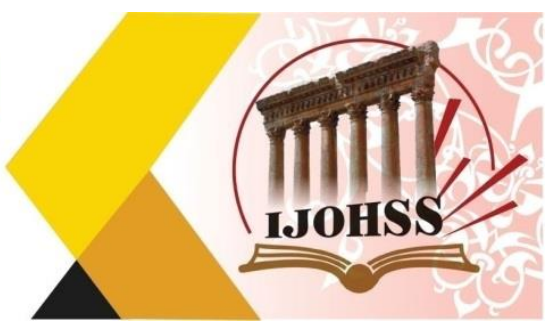

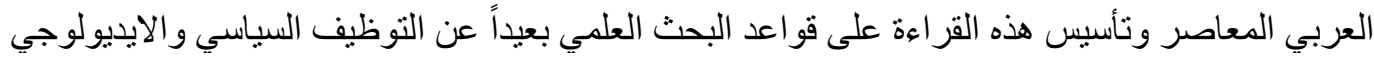

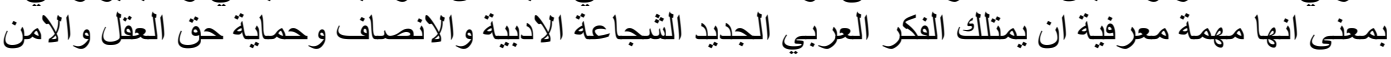

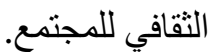

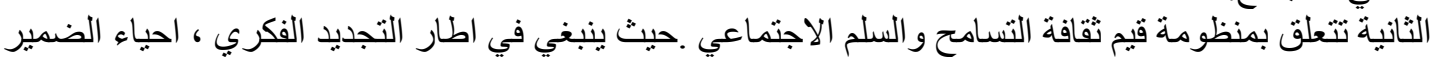

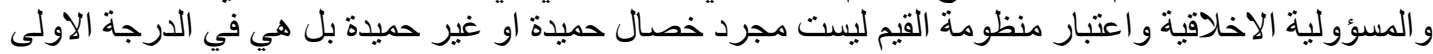

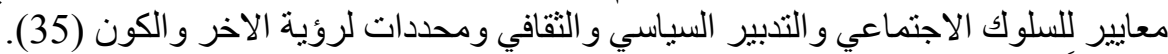

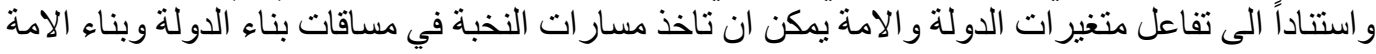

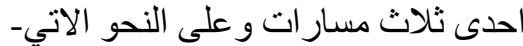

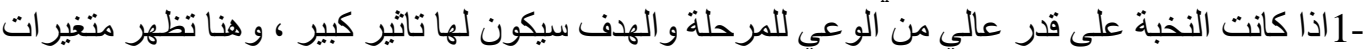

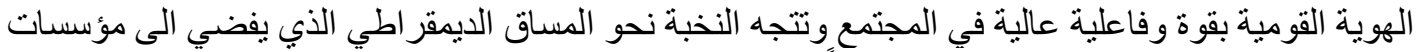

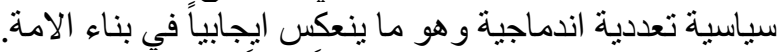

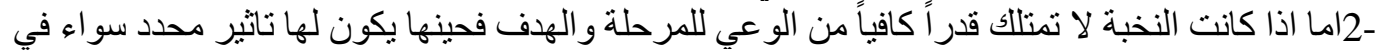

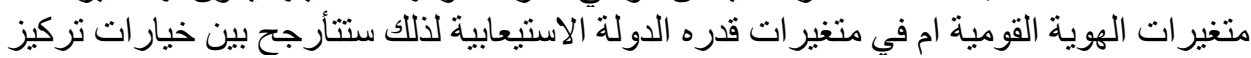

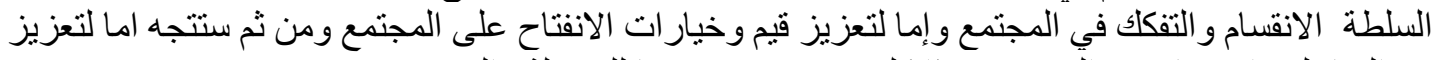

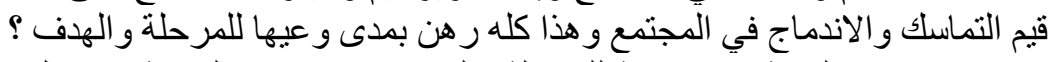

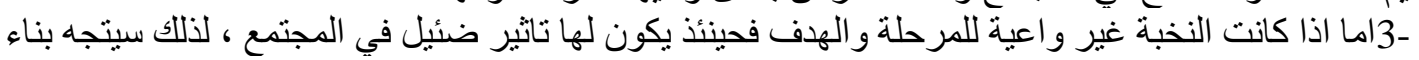

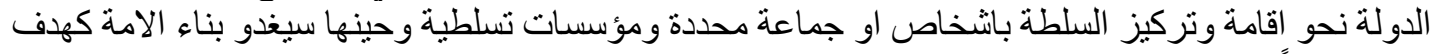

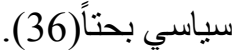

و عليه، تقوم المجتمعات المعاصرة على الماتى دعامتين مركزيتين.

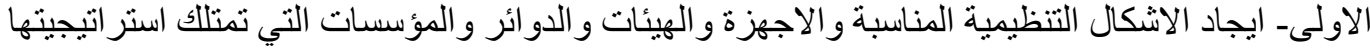

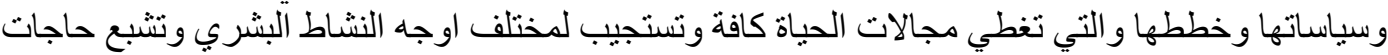

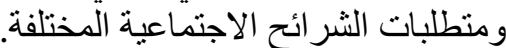

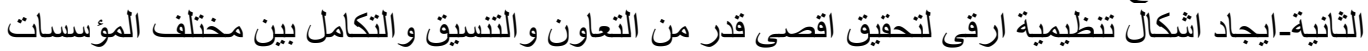

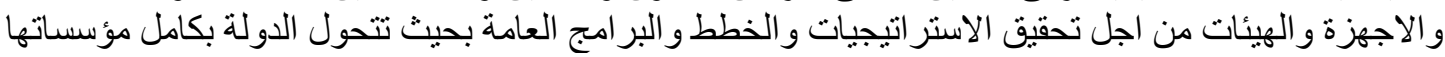

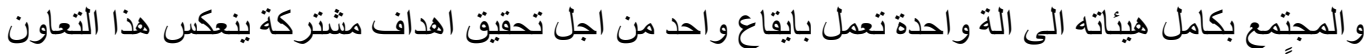

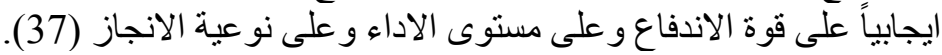

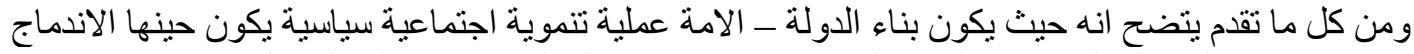

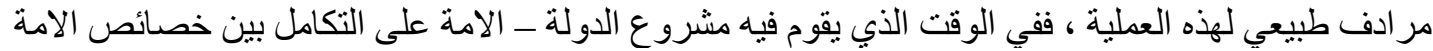

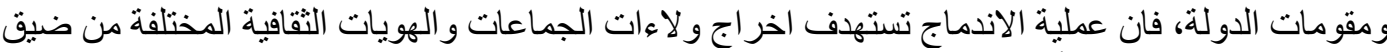

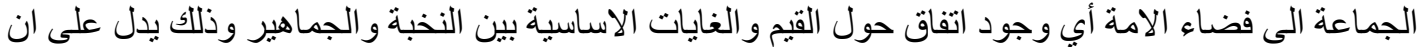

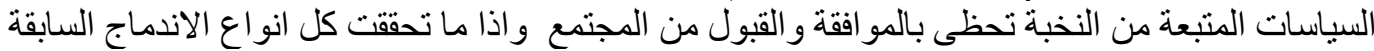

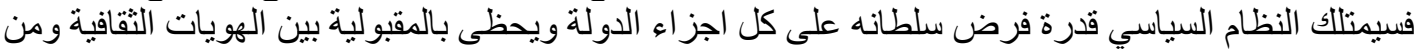

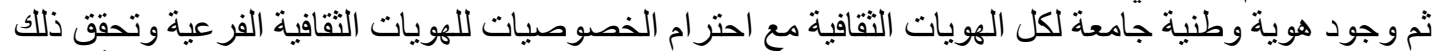

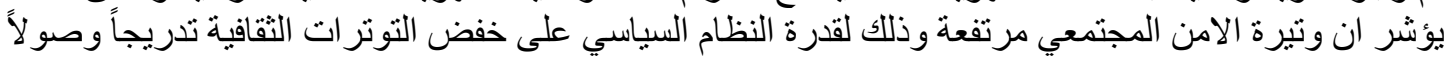
الى انهائها ويتحقق ذلك في حالة الاتفاق العام حول القيم و الغايات الآساسية (38).

الخاتمة

مما تقدم يتضح ما يلي

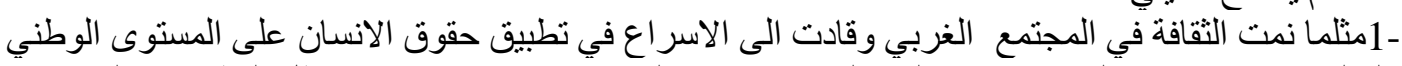

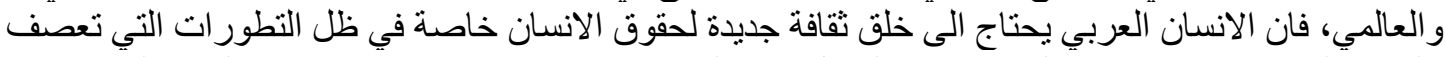

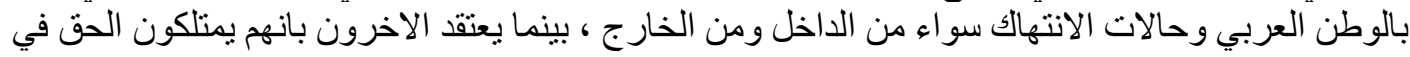


International Journal on Humanities and Social Sciences

website:www.ijohss.com

Email:editor@ijohss.com

العدد(22) يوليو 2021

ISSN: $2415-4822$

Volume (22) July 2021

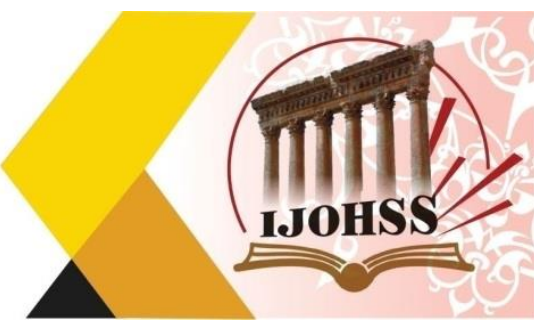

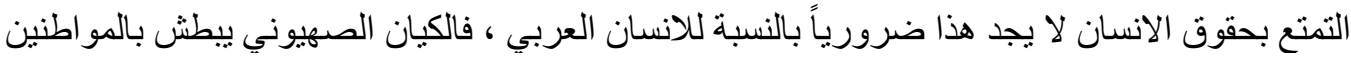

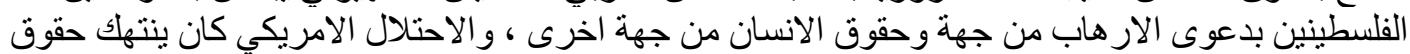

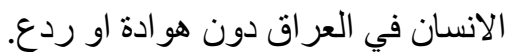

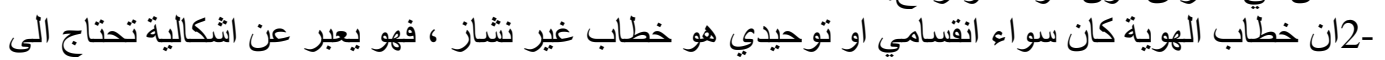

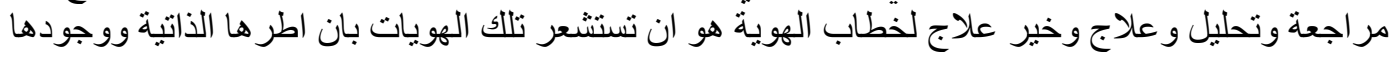

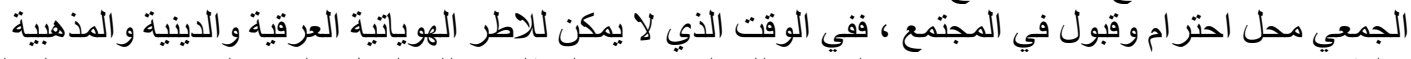

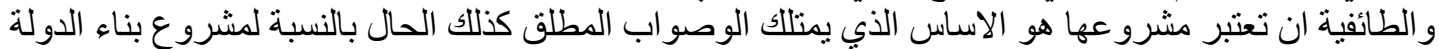

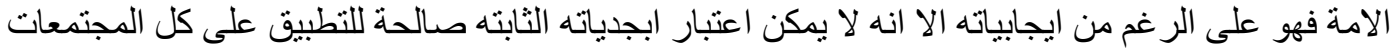

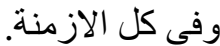

-3ان بناء السلام في المجتمعات المتصار عة لم يعد مطلب و انما ضرورة حتمية للحفاظ على حالة السلام

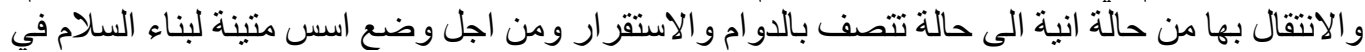

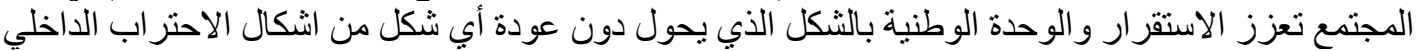

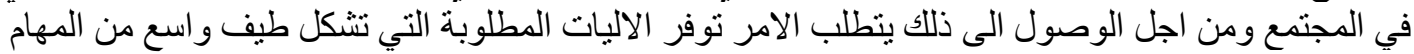

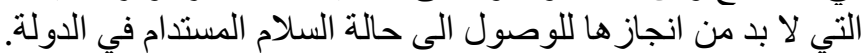

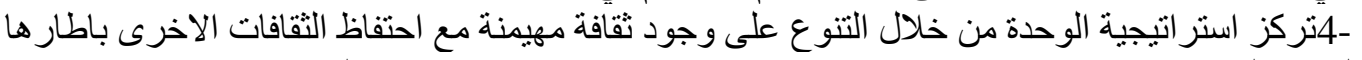

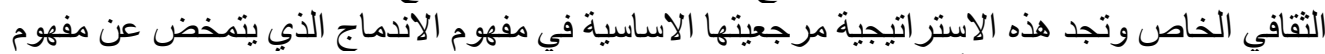

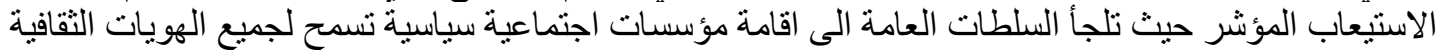

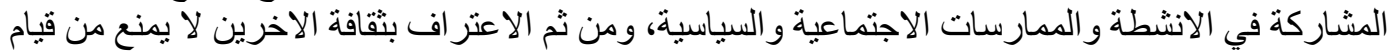
ثقافة عليا مهيمنة تدفع نحو التعايش التقافي.

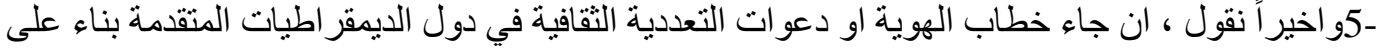

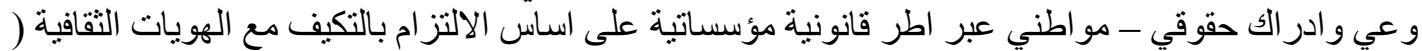

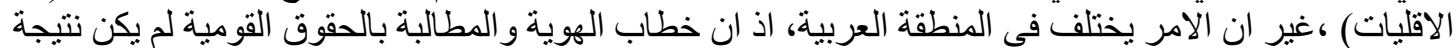

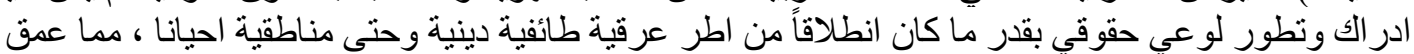

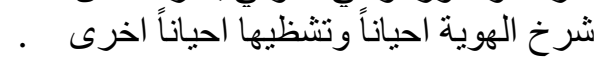

\section{الهو امش والمصادر}

-1 سعدي ابر اهيم حسن، الفدر الية النظام الاتحادي و الهوية الوطنية العر اقية من يوقف النار قبل ان تحرق

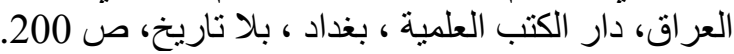

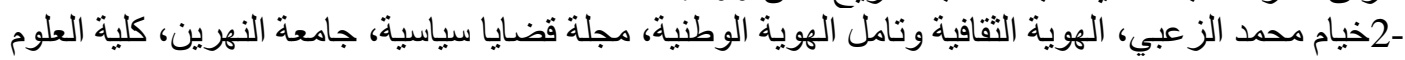

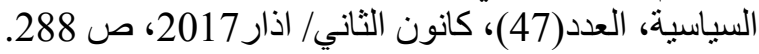

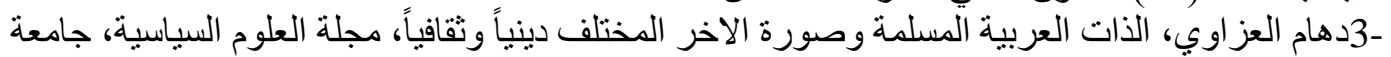

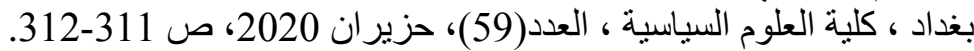

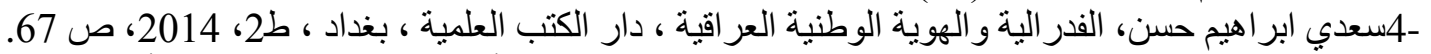

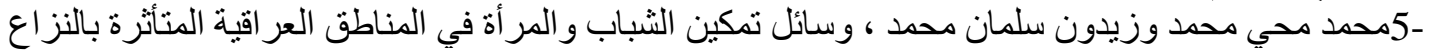

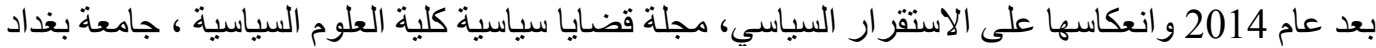

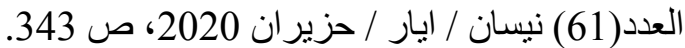
-6توات عثمان ، مؤشر الفقر متعدد الابعاد منظون منظور جديد للتحليل ، مجلة المستقبل العربي / سبتمبر 2020، ص 33 ص 33

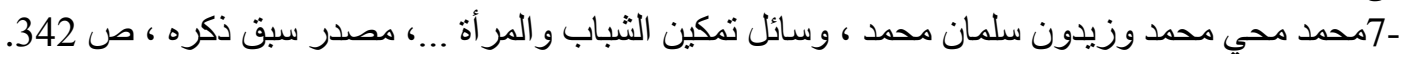

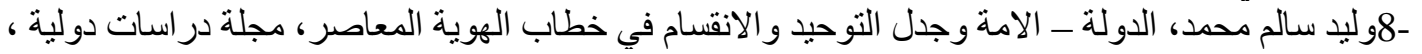

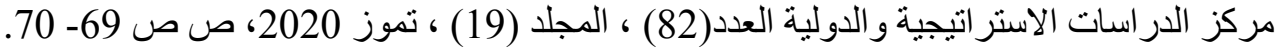


International Journal on Humanities and Social Sciences

website:www.ijohss.com

Email:editor@ijohss.com

العدد(22) يوليو 2021

ISSN: $2415-4822$

Volume (22) July 2021

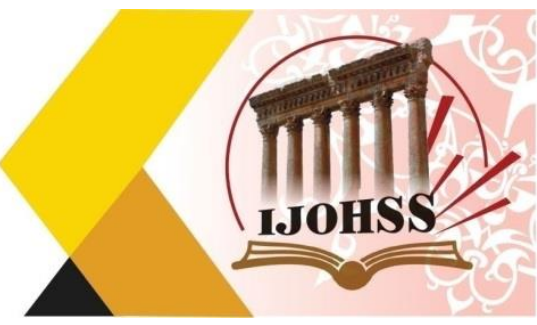

-91اركان هادي البدري، خطاب الكراهية في نطاق القانون الدولي الجنابي، مجلة العلوم القانونية السياسية،

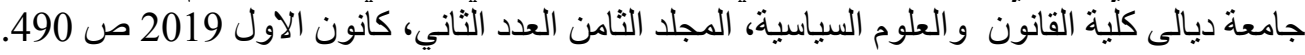

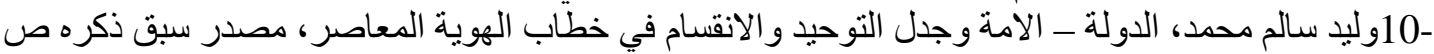

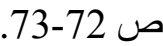
-11سالم كبارة، سوسيولوجيا الهوية جدليات الوعي و التفكك و اعادة البناء، مجلة المستقبل العربي، لسنة (40) ،

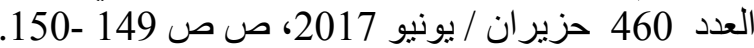

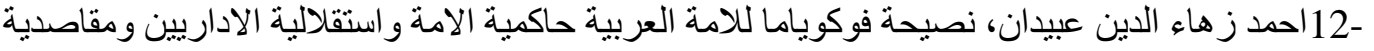

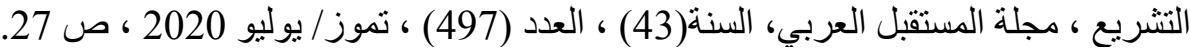

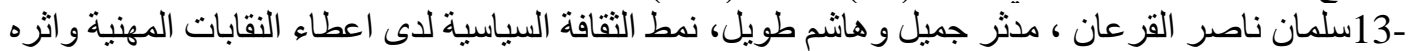

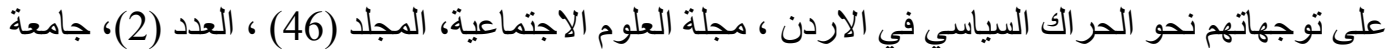

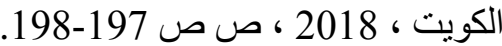

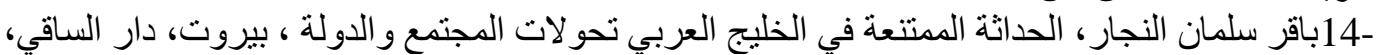

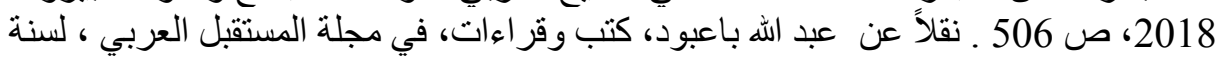

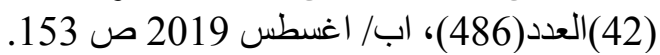

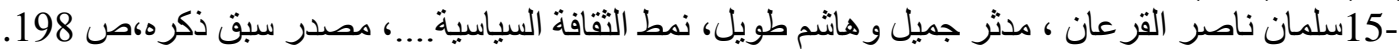

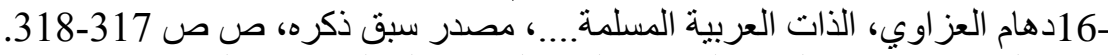

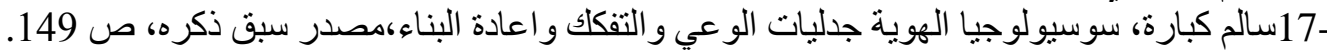

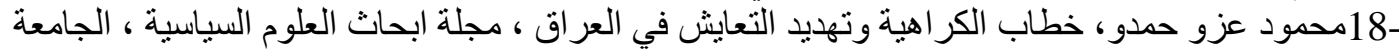

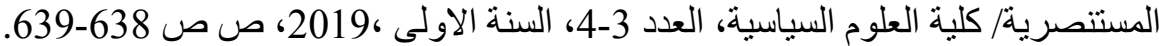
-19رقية سعيد، منظومة الهوية و علاقتها بالديمقر اطية في الفكر السياسي، مجلة قضايا سياسية كلية العلوم

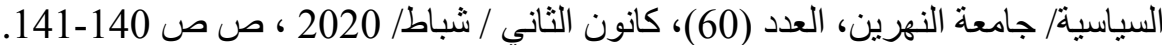

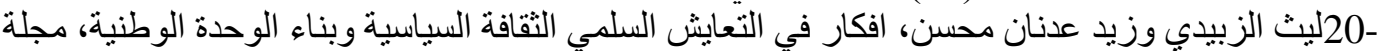

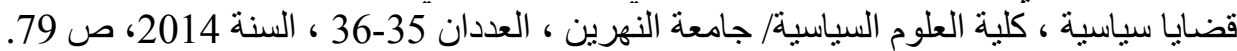
-21 علي اومليل، السلطة الثقافة و السلطة السياسية، مركز دراسات الوحدة العربية، بيروت ،

922. وليد سالم محمد، الثقافة السياسية واهميتها في مأسة السلطة وبناء الدولة في العراق ، المجلة العربية للعلوم

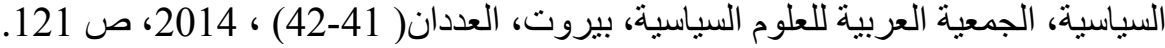

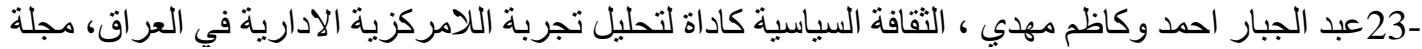

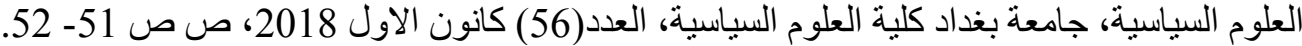

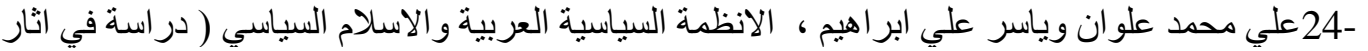

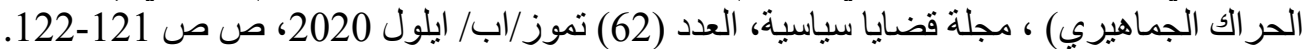

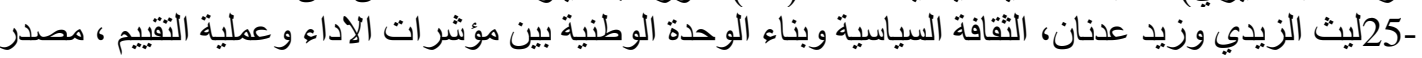

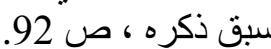

-26الامير الحسن بن طلال، الثباب العربي وصون الفكر العربي، مجلة المستقبل العربي، السنة (40) ، العدد

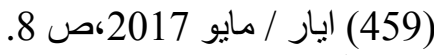

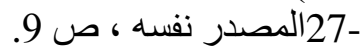

-28 عبد الحسين شعبان، ادارة التنوع في المجتمعات المتعددة الثقافات، مجلة قضايا سياسية ، العدد (56) ،

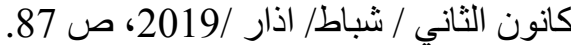

-29باسم خرسان ، بناء السلام در اسة في آليات بناء الساء السام في العر اق ، مجلة قضايا سياسية، العدد (52)

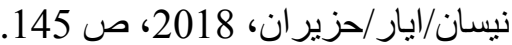

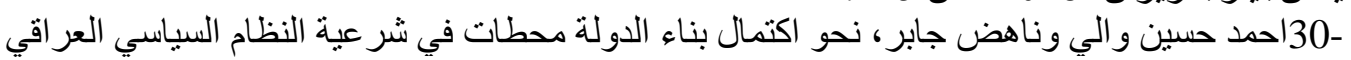

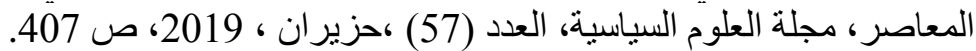

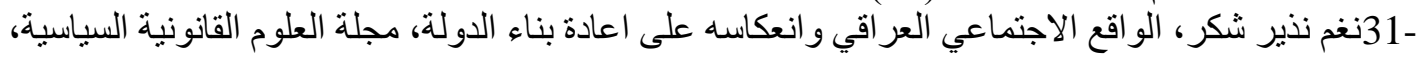




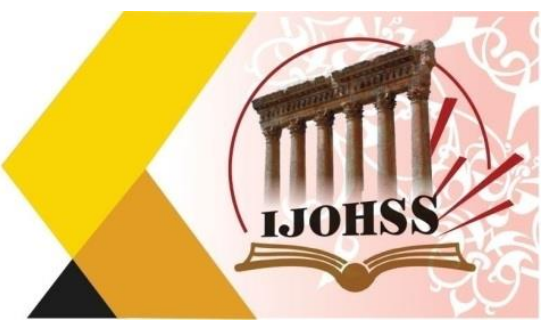

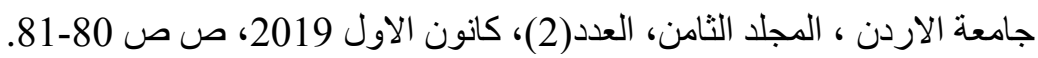

-32يوسف الحسن، دور المثقفين في تجديد الفكر العربي، مجلة المستقبل العربي، العدد (891) ، العبن السنة (420)

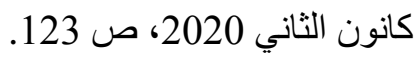

-33نشريفة فاضل بلاط ، دور الامن الفكري في مو اجهة الار هاب الدولي، المجلة العربية للعلوم السياسية ،

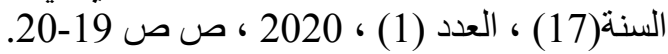

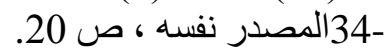

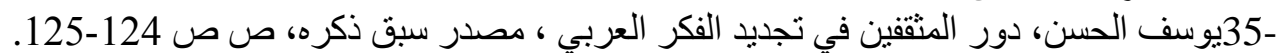

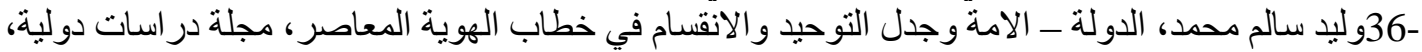

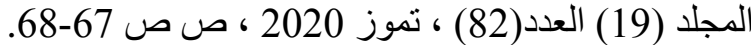
37-37نوح عز الدين، الاعلام العربي و التحديات الامنية، مجلة در اسات سياسية واستر اتيجية، بيت الحكمة، العدد

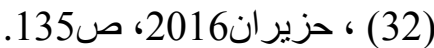
-38وليد سالم محمد، الدولة ـ الامة وجدل التوحيد و الانقسام....؟ مصدر سبق ذكره ص ص 68- 69.

\section{References}

1- Saadi Ibrahim Hassan, Federalism The Federal System and the Iraqi National Identity Who Stops the Fire Before It Burns Iraq, Dar al-Kutub al-Ilmiyya, Baghdad, no history, p. 200.

2- Khayyam Muhammad Al-Zoubi, Cultural Identity and National Identity Reflections, Journal of Political Issues, Al-Nahrain University, College of Political Science, Issue (47), January/March 2017, p. 288.

3- Daham Al-Azzawi, The Arab Muslim Self and the Image of the Religiously and Culturally Different Other, Journal of Political Science, University of Baghdad,

College of Political Science, Issue (59), June 2020, pp. 311-312.

4- Saadi Ibrahim Hassan, Federalism and Iraqi National Identity, Dar al-Kutub alIlmiyya, Baghdad, 2nd Edition, 2014, p. 67.

5- Muhammad Muhyi Muhammad and Zaidoun Salman Muhammad, The means of empowering youth and women in the Iraqi regions affected by the conflict after 2014 and their reflection on political stability, Journal of Political Issues, College of Political Science, University of Baghdad, Issue (61) April / June 2020, p. 343. 6- Tawat Othman, The Multidimensional Poverty Index: A New Perspective for Analysis, Arab Future Magazine / September 2020, p. 33.

7- Muhammad Muhyi Muhammad and Zaydun Salman Muhammad, Means of Empowering Youth and Women..., a previously mentioned source, p. 342.

8- Waleed Salem Muhammad, The State - The Nation and the Controversy of Unification and Division in Contemporary Identity Discourse, Journal of International Studies, Center for Strategic and International Studies, Issue (82), Volume (19), July 2020, pp. 69-70.

9- Arkan Hadi Al-Badri, Hate Speech within the Context of International Jurisprudence, Journal of Political Legal Sciences, University of Diyala, College of Law and Political Science, Volume Eight, Issue Two, December 2019, p. 490. 


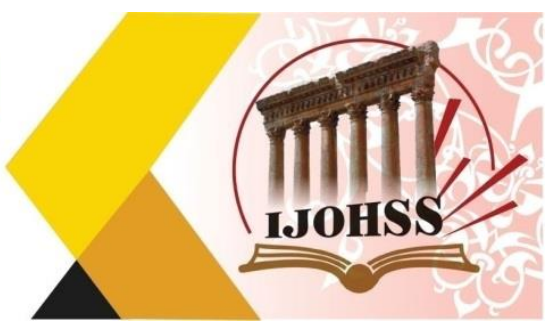

10- Waleed Salem Muhammad, The State - The Nation and the Controversy of Unity and Division in the Contemporary Identity Discourse, aforementioned source, pp. 7273.

11- Salem Kabbara, The Sociology of Identity: Dialectics of Consciousness, Disintegration and Reconstruction, The Arab Future Magazine, for the year (40), Issue 460, June 2017, pp. 149-150.

12- Ahmed Zaha Al-Din Obaidan, Fukuyama's Advice to the Arab Nation, The Nation's Governance, Administrative Independence, and Legislation Purposes, Journal of the Arab Future, Al-Sunnah 43, Issue (497), July 2020, p. 27.

13- Salman Nasser Al-Qar'an, Mudassir Jamil and Hashem Tawil, The pattern of political culture when giving professional unions and its impact on their attitudes towards political mobility in Jordan, Journal of Social Sciences, Vol. (46), No. (2), Kuwait University, 2018,pg. 198.

14- Baqir Salman Al-Najjar, Refraining Modernity in the Arabian Gulf, Transformations of Society and the State, Beirut, Dar Al-Saqi, 2018, p. 506. Quoted from Abdullah Baaboud, Books and Readings, in the Arab Future magazine, for the year (42) Issue (486), August / August 2019, p. 153.

15- Salman Nasser Al-Qar' an, Muddathir Jamil and Hashem Tawil, The Pattern of Political Culture...., a previously mentioned source, p. 198.

16- Daham Al-Azzawi, The Arab Muslim Self...., a previously mentioned source, pp. 317-318.

17- Salem Kabara, The Sociology of Identity: Dialectics of Consciousness,

Disintegration and Reconstruction, a previously mentioned source, p. 149.

18- Mahmoud Ezzo Hamdo, Hate Speech and the Threat to Coexistence in Iraq, Journal of Political Science Research, Al-Mustansiriya University / College of Political Science, Issue 3-4, Year 1, 2019, pp. 638-639.

19- Ruqayya Saeed, The Identity System and its Relationship to Democracy in Political Thought, Journal of Political Issues, College of Political Science / AlNahrain University, Issue (60), January / February 2020, pp. 140-141.

20- Laith Al-Zubaidi and Zaid Adnan Mohsen, Ideas of Peaceful Coexistence,

Political Culture and Building National Unity, Journal of Political Issues, College of Political Science/Al-Nahrain University, Nos. 35-36, Year 2014, p. 79.

21- Ali Omlil, Culture and Political Authority, Center for Arab Unity Studies, Beirut, 1, 1998, p. 9.

22- Walid Salem Muhammad, Political Culture and its Importance in the Tragedy of Power and State Building in Iraq, The Arab Journal of Political Science, The Arab Association for Political Science, Beirut, Issues (41-42), 2014, p. 121.

23- Abdul-Jabbar Ahmed and Kazem Mahdi, Political culture as a tool for analyzing the experience of administrative decentralization in Iraq, Journal of Political Science, University of Baghdad, College of Political Science, Issue (56) December 2018, pp. 51-52. 


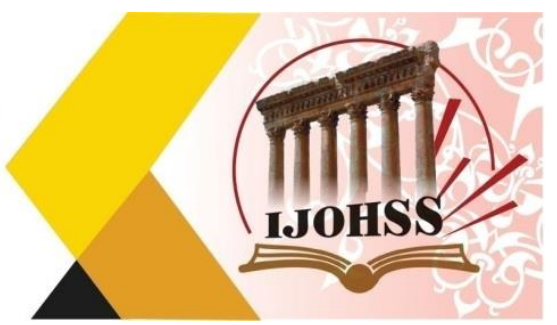

24- Ali Muhammad Alwan and Yasser Ali Ibrahim, Arab Political Systems and Political Islam (A Study in the Effects of Mass Mobility), Political Issues Journal, Issue (62) July/August/September 2020, pp. 121-122.

25- Laith Al-Zaidi and Zaid Adnan, Political Culture and Building National Unity between Performance Indicators and the Evaluation Process, a previously mentioned source, p. 92.

26- Prince Hassan bin Talal, Arab Youth and Preserving Arab Thought, Arab Future magazine, year (40), issue (459), May 2017, p. 8.

27- The same source, p. 9.

28- Abdul-Hussein Shaaban, Managing Diversity in Multicultural Societies, Political Issues Journal, Issue (56), January/February/March/2019, p. 87.

29- Bassem Khurasan, Peacebuilding, A Study of Peacebuilding Mechanisms in Iraq, Political Issues Journal, No. 52, April/June, 2018, p. 145.

30- Ahmed Hussein Wali and Nahed Jaber, Towards the Completion of State Building, Stations in the Legitimacy of the Contemporary Iraqi Political System, Journal of Political Science, Issue (57), June, 2019, p. 407.

31- Nagham Nazir Shukr, The Iraqi Social Reality and Its Reflection on Rebuilding the State, Journal of Political Legal Sciences, University of Jordan, Volume VIII, Issue (2), December 2019, pp. 80-81.

32- Youssef Al-Hassan, The Role of Intellectuals in Renewing Arab Thought, Arab Future Magazine, Issue (491), year (42) January 2020, p. 123.

33- Sharifa Fadel Blat, The Role of Intellectual Security in Confronting International Terrorism, The Arab Journal of Political Science, Year (17), No. (1), 2020, pp. 19-20. 34- The same references, pg. 20.

35- Youssef Al-Hassan, The Role of Intellectuals in Renewing Arab Thought, a previously mentioned source, pp. 124-125.

36- Walid Salem Muhammad, The State - The Nation and the Controversy of Unification and Division in Contemporary Identity Discourse, Journal of International Studies, Volume (19) Issue (82), July 2020, pp. 67-68.

37- Noah Ezz El-Din, Arab Media and Security Challenges, Journal of Political and Strategic Studies, House of Wisdom, No. 32, June 2016, p. 135.

38- Waleed Salem Muhammad, The State - The Nation and the Controversy of Unification and Division....? A previously mentioned source pp. 68-69. 